Thorax (1952), 7, 334.

\title{
SOME OBSERVATIONS ON THE HISTORICAL APPRECIATION PATHOLOGICAL DEVELOPMENT, AND BEHAVIOUR OF ROUND TUBERCULOUS FOCI
}

\author{
BY \\ W. M. MACLEOD AND A. TAIT SMITH \\ from the Thoracic Unit, St. Thomas's Hospital, London
}

(RECEIVED) FOR PUBLICATION MARCH 13. 1952)

The recognition of the tubercle as a feature of the morbid anatomy of pulmonary tuberculosis appears to date from the observations of Franciscus Delaboe Sylvius in 1679 (Webb, 1936). He describes "tubercula" as tiny diseased lymph nodes in the lungs which were wont to increase with age and suppurate. Richard Morton (Phthisiologia, 1689) comments on the formation of "crude tubercles":

"For the most part these tubercles are glandulous tumours of a chronic and cold nature ... the humor stagnating within them is gradually concocte 1 by the natural heat of the part into the form of chalk, or into a substance like suet or like honey. and yet is always contained in a proper bag."

A hundred years later William Stark (1788), in an essay published posthumously, writes:

" In the cellular substance of the lungs are found roundish firm bodies (named tubercles) of different sizes from the smallest granule. to about half an inch in diameter."

These observations were made at post-mortem examinations on advanced cases of phthisis : even so Bayle (1810) notes that the foci, which may be as large as chestnuts, are sometimes few in number. only two or three being present. Laennec (1819) comments on the rarity of finding "encysted tubercles " in an otherwise healthy lung, and on the greater rarity of finding tubercles of any appreciable size before they have discharged their contents. In a later chapter, however, he discusses the not infrequent finding of chalky and pultaceous lesions, some as big as hazelnuts, which "cysts," he believed. were the consequences of healed tuberculosis.

Virchow (1864-65) described conglomerate tubercles as large macroscopic lesions formed by the conglomeration of thousands of smaller tubercles. He gives as an example a detailed description of a cerebral "tuberculoma," which is apparently almost identical with many of the pulmonary round foci. What is now termed the "blocked cavity" is considered by Birch-Hirsch- 3 feld (1882), in his textbook of pathological anatomy, as a cavity filled with a caseous mass -a healing process which he believed could remain $\stackrel{\oplus}{0}$ unchanged for a long time. Küss (1898), in his? detailed studies of the primary tuberculous comp'ex, describes the focus as a single caseous lesion with a fibrous capsule, sometimes as large as a hazelnut. In children it is overshadowed by the marked adenitis, while in adults the focus itself may be the dominant feature, the glands being insignificant.

By the beginning of the twentieth century round tuberculous foci were being recognized as granulomata, as encapsulated caseous pneumonia. as blocked cavities, or as primary foci

The development of chest radiology naturally focused attention on the earlier stages of pulmonary tuberculosis. Assmann called attention to the importance of infra-clavicular shadow's as a feature of early phthisis. He described (1925) a round shadow of uniform density in the upper lung fields below the outer part of the clavicle. as large as a "three-mark p.ece." and occasionally surrounded by pinhead flecks. The shadow might clear in the centre to form a ring, could remain. becoming sharper and more defined, or become smaller and eventually heal with scar formation. He presumed the focus to consist of an area of caseous pneumonia. Following Assmann's communication were numerous papers in the German literature discussing the nature of these foci. Pagel (1931) suggested that the persistent round focus was a large reinfective focus and was not a primary lesion, as there was no associated involvement of the glands.

In America Wessler and Jaches (1923) also recognized the round focus and believed it represented incipient tuberculosis. In addition they 
noticed cases with multiple round foci, suggestive of secondary deposits, but which were in fact tuberculous. Further reports of multiple round foci, proved or presumed tuberculous, followed (von Jacksch-Wartenhorst, 1927 ; Albert, 1931 ; Lachmann, 1931 ; Bruck, 1934 ; von Hecker and Kellner, 1929).

The interest aroused by these earlier papers is reflected in numerous articles discussing the various features of round foci. Their origin and development, whether primary or reinfective foci, haematogenous or bronchogenic, their place in the natural history of phthisis, their innocence or deceit, are all considered at length (Straub, 1932 ; Klein and Wolff, 1934 ; Birkelo and Kasper, 1937 ; Uehlinger, 1939 ; Bobrowitz, 1943).

More recently interest has been further intensified. The present wave of resection in pulmonary tuberculosis has given unparalleled opportunities for the more precise study of early phthisis. The radiological shadow becomes the pathological specimen. The round focus falls into this group, and we have taken advantage of this opportunity.

\section{The Present Study}

Our material consists of 14 cases, all of which have been seen in the Thoracic Unit of St. Thomas's Hospital in the past five years. While most of the patients were living in the dispensary area of North Lambeth, our figures must not be taken as giving the true incidence of round foci. Eight of the cases were operated on and the round focus resected. They are all reported. The remaining six were selected from some 20 unoperated cases.

The case reports are confined to the relevant findings. Measurements are taken from routine postero-anterior films or, where stated, from a tomographic section. Interspaces refer to the spaces between the anterior parts of the ribs. Only dense areas are interpreted as calcification, such being the common practice. Erythrocyte sedimentation rate readings are all taken at the end of one hour, using a $200 \mathrm{~mm}$. Westergren tube. Streptomycin is recorded as the total dose. In all such cases the routine was $1 \mathrm{~g}$. of streptomycin and 20 g. of P.A.S. daily, given for six days of each week.

All of the specimens examined have microscopic sections stained by haematoxylin and eosin, by Van Gieson's method, by a modification of Foot's method for reticulin fibres, by the Ziehl-Neelsen method for tubercle bacilli, and by Gram's method for other organisms. By using the silver method for reticulin fibres it is possible to observe struc- ture which has been conserved in dead tissue. This conservation of structure may also be seen in a ghostly way in haematoxylin-and-eosin-stained sections or by indirect illumination, but the mummified nature of the lesions to be described is not clear until silver impregnation is carried out. Gold toning improves the microscopic picture.

The specimens examined as above showed that the necrotic tissue which forms the core of most of the lesions presents three appearances. (1) An interlacing fibrous network encloses poorly defined giant cells. In some places the fibres are scanty and fine, in others they are coarse, abundant, and closely entwined. This is the ghost of tuberculous granulation tissue (Fig. 1). (2) First, the alveolar structure of the lung is conserved. The alveoli are packed with poorly outlined cells. The alveolar walls are not thickened (Fig. 2). This is evidently the ghost of a bronchopneumonia. Fig. 3 is a section of normal lung impregnated in the same way for comparison. Secondly, the alveolar structure of the lung is conserved, but the walls of the alveoli are thickened by the addition of new fibrous structure and the mass within the alveoli is intersected with fine fibres (Fig. 4). This is the ghost of a bronchopneumonia in which organization has been in progress. (3) The mass is completely amorphous without evidence of fibre structure or lining alveoli. Areas having this appearance have in our examples been sharply demarcated from areas of necrosis with conserved structure. There is no gradual shading from one into the other (Fig. 5). Amorphous necrotic tissue has been seen generally well away from the edge of the lesion, sometimes quite in the centre of the necrotic areas. It has been found in both kinds of necrotic tissue having the conserved structure. Where the amorphous necrotic tissue has been eccentrically placed and in relation to a bromchus, liquefaction and evacuation into the bronchus has sometimes occurred (Fig. 6). The conspicuous feature of those parts of the necrotic tissue which show no structure after silver impregnation has been the presence in them of acid-fast bacilli, in some cases in very large numbers. In a completely enclosed lesion it has been a remarkably constant feature that, in necrotic areas in which the structure is conserved, acid-fast bacilli are not demonstrable, or demonstrable only after long search, but, in amorphous necrotic areas in the same microscopic field, acid-fast bacilli are present in large numbers. This amorphous necrotic tissue evidently represents a stage intermediate between necrosis with conservation of structure and liquefaction (Fig. 7). 


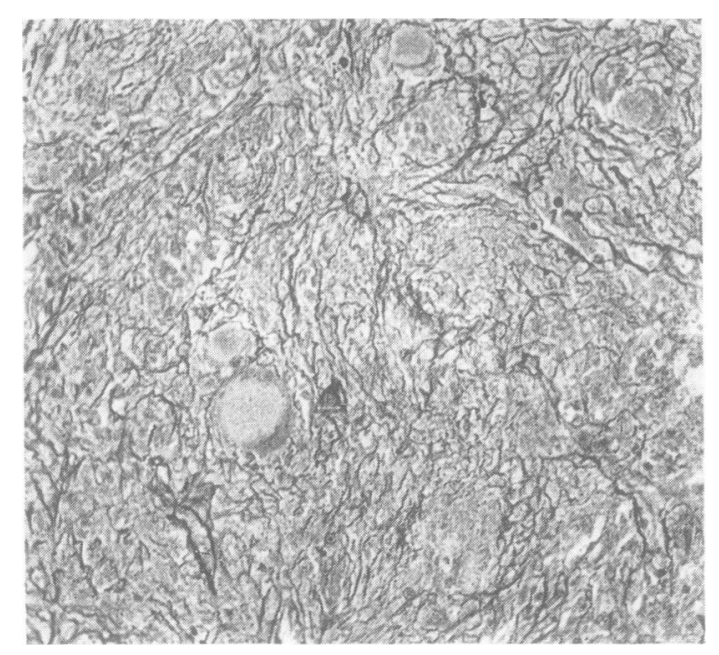

I

FIG. 1

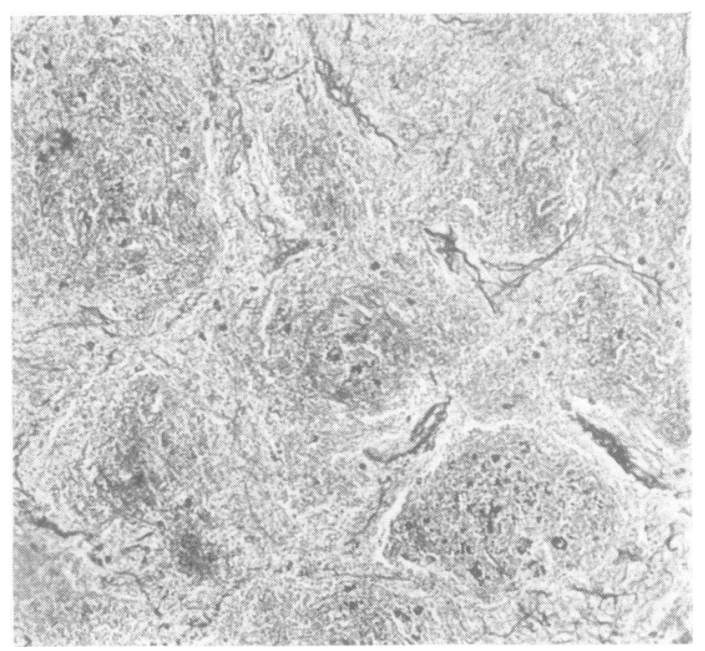

FIG. 2

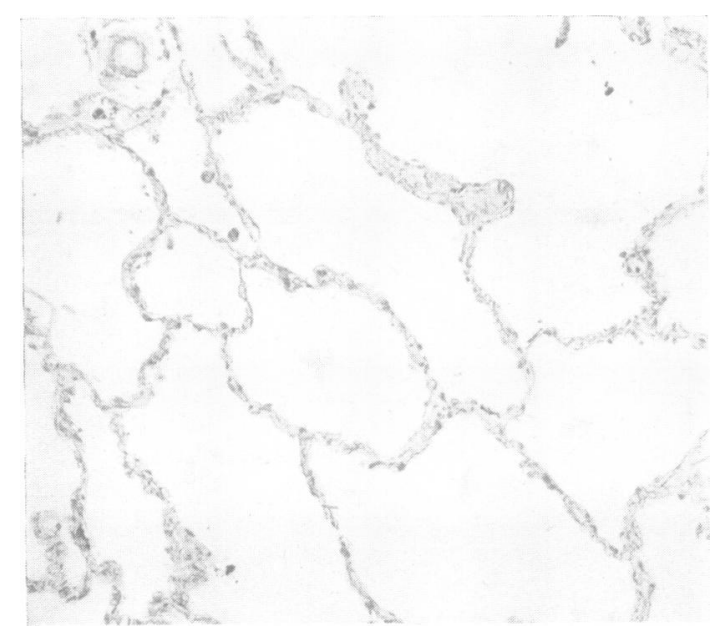

FIG. 3

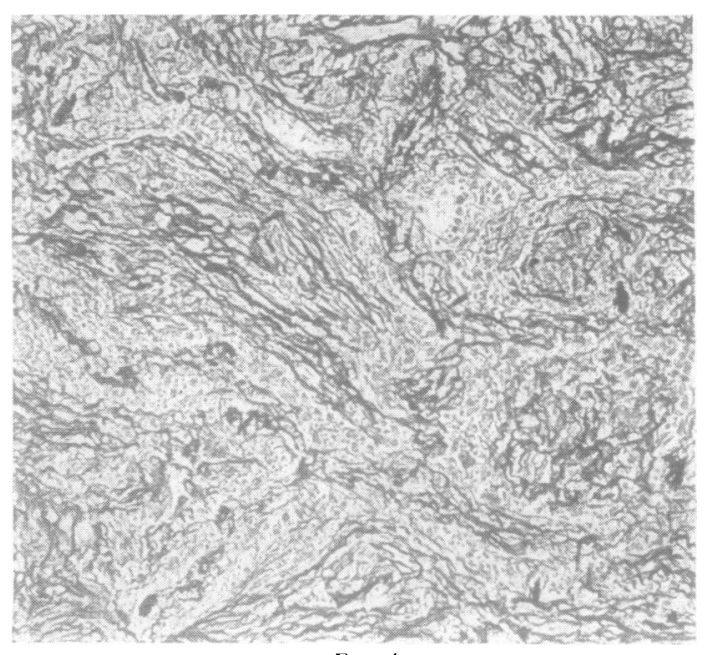

FIG. 4

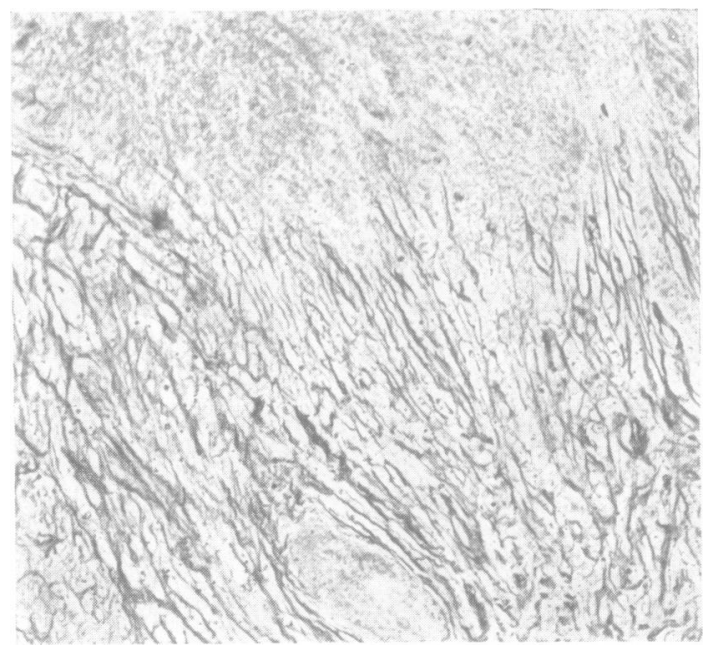

Fic; 5

Fig. 1.-The ghost of tuberculous granulation tissue. Necrotic tissue 을. in which the fibrillar structure and ghosts of giant cells are conserved. Silver impregnation.

FIG. 2.-An average example of necrotic tissue with conservation of alveolar structure. Silver impregnation. nation.

FIG. 4-Necrotic tissue in which the alveolar structure has been conserved. Fibres are present within the alveoli. Silver impregnation.

Fic. 5.-The sudden transition from necrotic tissue, in which the $\mathbb{D}$ structure is conserved, to amorphous caseous material. Silver $\varrho$ impregnation. 


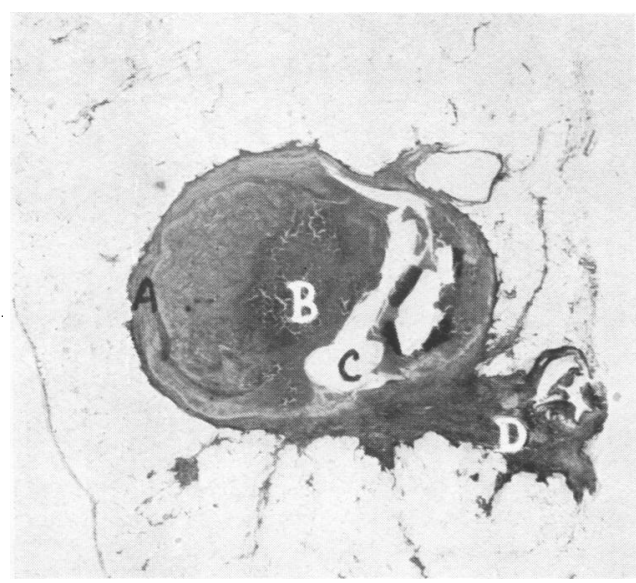

Fig. 6.-Photomicrograph of section from Case 4. Different zones may be seen after silver impregnation. A. Necrosis with conserved structure. B. Amorphous caseous material. C. Zone of liquefaction. D. The associated bronchus.

Gross examination of these areas was correlated with the microscopic findings. Those parts which are microscopically amorphous are slightly softer and more homogeneous than the peripheral parts in which the structure is conserved in the necrotic tissue. The colour is creamy yellow. It is typical caseous material. Those parts which are necrotic but which have their structure conserved are paler in colour and their fibrous structure is demonstrable by picking with the point of a knife.

\section{CASE RePorts}

Case 1.- J.W., a coalman aged 44, was well until April, 1951, when, while at work, he felt a click in the left chest and coughed up a teaspoonful of blood. The radiograph showed a rounded lesion $2 \mathrm{~cm}$. in diameter through the left ventricular shadow (Fig. 8). It was situated in the posterior segment of the left lower lobe. Bronchoscopic examination was normal. Thoracotomy was carried out on May 28, 1951, the tumour being enucleated. Calcified glands were noted in the hilum. Convalescence, with streptomycin, was uneventful (36 g.).

The specimen received was a spherical mass $1.7 \mathrm{~cm}$. in diameter, quite hard, gritty, and yellow. A segment of the sphere, $0.5 \mathrm{~cm}$. deep, had a lamellar structure, evidently of pleural origin. The greater part of the lesion had its origin in the lung. An irregular central mass of yellow material, partly calcified, was enclosed by two concentric pale broad laminae of similar texture, partly calcified, with a thin pigmented lamina between them. It was seen microscopically that the yellow mass was necrotic. It was surrounded by a thin zone of pigmented fibrous tissue with a lamellar arrangement infiltrated by lymphocytes and an occasional giant cell. The outlying lung was normal.

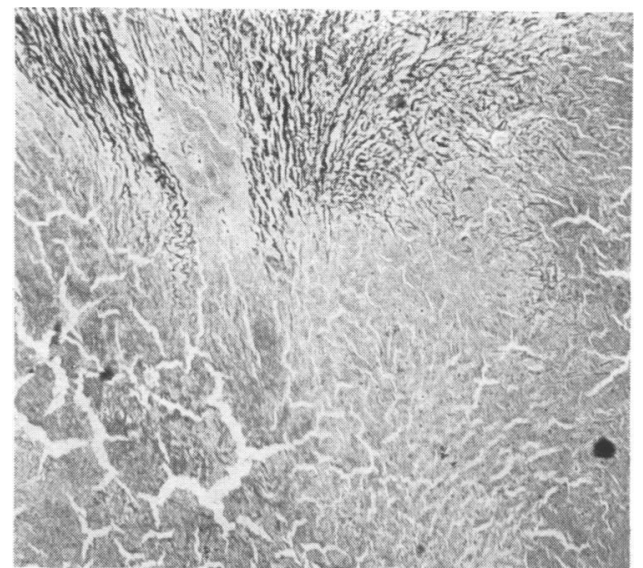

FIG. 7.-A higher magnification of Fig. 6 to show the transition between the different zones.

Silver impregnation of the necrotic mass showed conserved alveolar structure with patchy calcification. Structure of the pleura had been conserved. This had been greatly thickened by layer on layer of fibrous tissue. The periphery of the necrotic tissue consisted of two concentric laminae of interlacing fibres. In both layers calcification was present (cf. Fig. 32). There was an intervening thin pigmented layer. No acid-fast bacilli were seen.

A laminated round focus, pre-operatively indistinguishable from neoplasm. It was examined by thoracotomy and locally excised.

Case 2.-V.M., a schoolgirl, was aged 10 when first seen in 1947 as a symptom-free contact of her father,

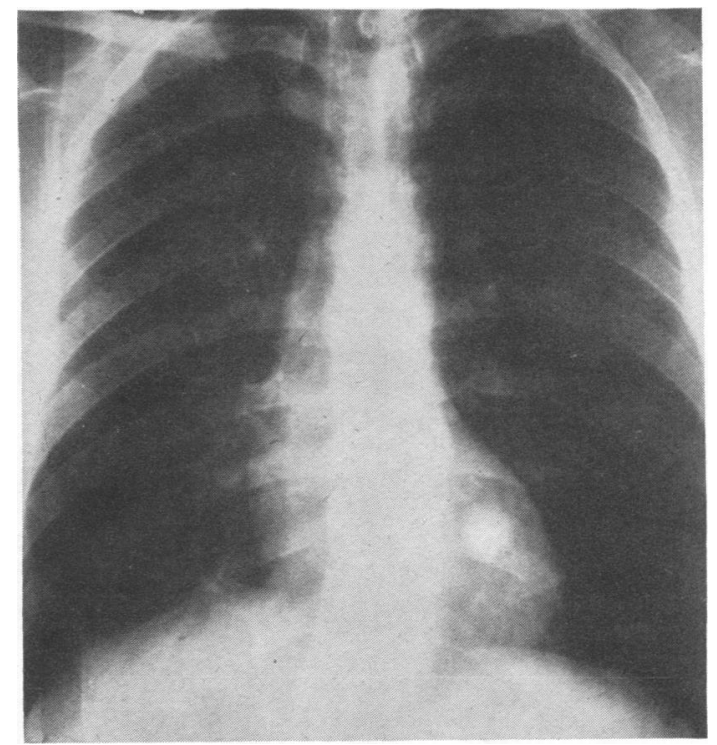

Fig. 8.-Radiograph of Case 1. A round focus, $2 \mathrm{~cm}$. diameter, can just be distinguished through the left ventricular shadow. 


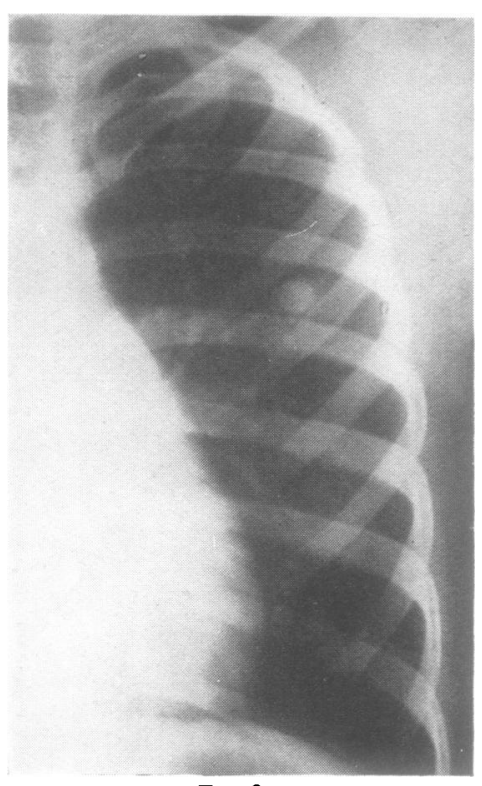

FIG. 9

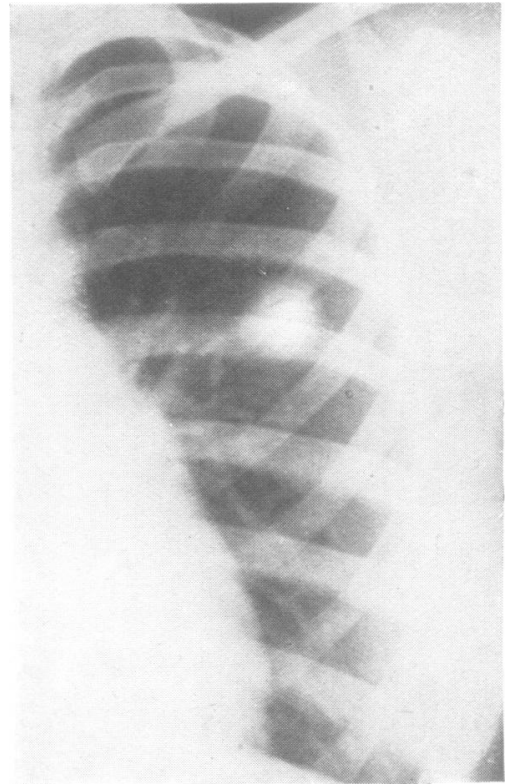

FIG. 10

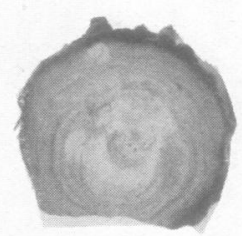

FIG. 11

Fig 9. Radiograph of Case 2 taken in August, 1947, showing a $1 \mathrm{~cm}$. round focus in the third left interspace.

FIG. 10.-Radiograph of Case 2 showing the growth of the lround [focus to $2 \mathrm{~cm}$. diameter by March, $1950,2 \frac{1}{2}$ years after picture in Fig. 9.

FIG. 11..-Specimen from Case 2 (actual o size). The laminated nature of the lesion is well seen.

who had open pulmonary tuberculosis. Radiography in August, 1947, showed a rounded lesion $1 \mathrm{~cm}$. in diameter with an ill-defined edge in the third left interspace (Fig. 9). In March, 1948, there was little change in size, but several denser flecks suggesting calcification had appeared. A year later (March, 1949) the radiograph showed that the focus was sharply defined and was now $2 \mathrm{~cm}$. in diameter. By March, 1950, the round focus had further enlarged, and several irregular areas of calcification were well seen (Fig. 10). In February, 1951, the shadow remained unchanged. She was operated on on March 5, 1951. The round focus was shelled out from the anterior segment. Calcified glands were noted in the hilum. Convalescence was uneventful under $100 \mathrm{~g}$. streptomycin.

The lesion was a pyriform mass with its apex immediately beneath the pleura. The main part of the mass was a dirty cream sphere with a diameter of $2.5 \mathrm{~cm}$. This part had a remarkable laminated appearance (Fig. 11). Broad, pale laminae alternating with thin,-darkly pigmented ones surrounded a small, structureless, pale yellowish, soft mass in the centre. Microscopic examination showed a large necrotic mass encapsulated by a thin zone of fibrous tissue infiltrated by lymphocytes and an occasional giant cell. The surrounding lung was normal.

Silver impregnation of the necrotic mass showed that its structure was conserved in part. There was a central amorphous mass, partly calcified, surrounded by laminae of the ghosts of tuberculous granulation tissue and of dense lamellar fibrous tissue in succession. The pigment was fixed in the lamellar fibrous tissue. Acid-fast bacilli were demonstrable in the central amorphous mass only. The peripheral outlying subpleural lesion was a characteristic ghost of alveolar pattern, partly calcified. There was no amorphous change. Acid-fast bacilli were not seen.

A laminated round focus which grew slowly over three years.

Case 3.-M.O'K., aged 35, was a dispenser, who had nursed tuberculous cases from 1940 to 1945. She was symptom-free. In August, 1950, a radiograph $\underset{\vec{\gamma}}{ }$ taken for emigration purposes showed a small focus $1 \mathrm{~cm}$. in diameter underlying the second rib in the $x$ right upper lobe. There were also a few scattered $\frac{0}{3}$ punctate lesions in both upper lobes, some calcified. Two months later the focus had enlarged to $2 \mathrm{~cm}$. in $§$ diameter, showing off-centre an area of translucency $0.5 \mathrm{~cm}$. in diameter (Fig. 12). By February, 1951, theo round focus had further increased to $2.5 \mathrm{~cm}$., while the translucent area had shrunk to $0.25 \mathrm{~cm}$. The Mantoux reaction was $1 / 1,000$ positive and the E.S.R. $2 \mathrm{~mm}$. An apical and posterior segmental resection $N$ was performed on August, 1951. Several enlarged glands were noted in the hilum, some being calcified. Convalescence, with 80 g. of streptomycin, was $\vec{\omega}$ uneventful.

The two upper segments of the right lung wereo examined. There was a spherical necrotic mass $\frac{\bar{\Phi}}{\Phi}$ $2.5 \mathrm{~cm}$. in diameter with one small irregular satellite $\stackrel{\infty}{+}$ $0.5 \mathrm{~cm}$. in diameter in the anterior segment. The surrounding lung was normal. The mass had a small ${ }^{-}$ irregular central cavity $0.5 \mathrm{~cm}$. in diameter filled with $\frac{\overrightarrow{\mathbb{D}}}{}$ a milky fluid. About the cavity was a small amount $\frac{\mathrm{P}}{\Phi}$ of caseous material. The greater part of the necrotic mass was formed of elastic, creamy-yellow tissue. The central part was pigmented and a peripheral $O$ pigmented lamina was present. A subsegmentaio 


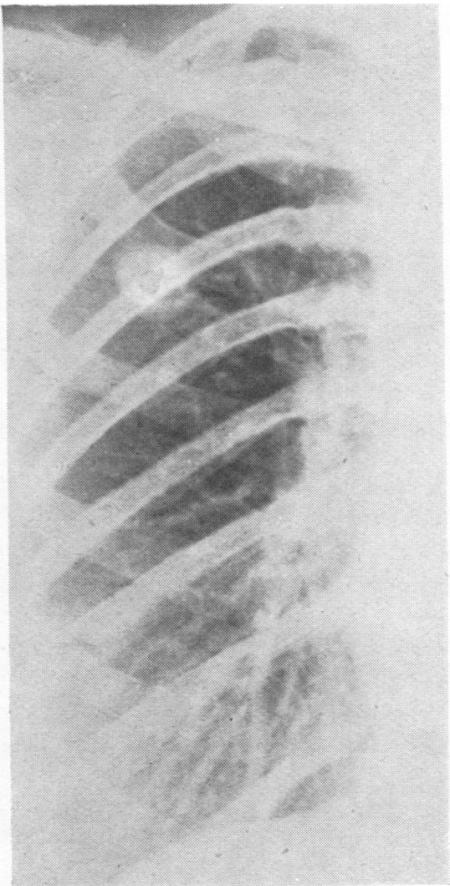

FIG. 12

bronchus was eccentrically placed in relation to this lesion which had infiltrated it (Fig. 13).

Microscopic examination showed a large necrotic mass surrounded by lymphocytes and containing some giant-cell systems. The surrounding lung was normal. The necrotic mass had its structure conserved in part. Silver impregnation revealed a central amorphous zone, partly liquefied, and containing masses of acidfast bacilli. It was surrounded by an inner zone in which the ghost of a bronchopneumonia was conserved. Outside this was the ghost of characteristic granulation tissue.

\section{A laminated round focus of fairly rapid growth.}

Case 4.-I.S., a housewife aged 26, on radiography in November, 1949, was reported as showing a small focus in the right upper lobe. Pregnancy was terminated on this account in March, 1950. She was first seen in April, 1950. A radiograph showed an oval lesion in the first right interspace, 1 by $1.5 \mathrm{~cm}$. It was of medium density, with a suggestion of calcification in the outer part. Sputum cultures were negative for $M$. tuberculosis. The E.S.R. was normal. The Mantoux reaction was $1 / 10,000$ positive. In October she developed a trace of sputum which was positive for $M$. tuberculosis, and radiography showed that the whole lesion had enlarged to $2 \mathrm{~cm}$. in diameter. The outer half showed well-marked calcification in its centre ; the inner half showed a round $0.5 \mathrm{~cm}$. translucency (Fig. 14). She was treated with streptomycin (83 g.).

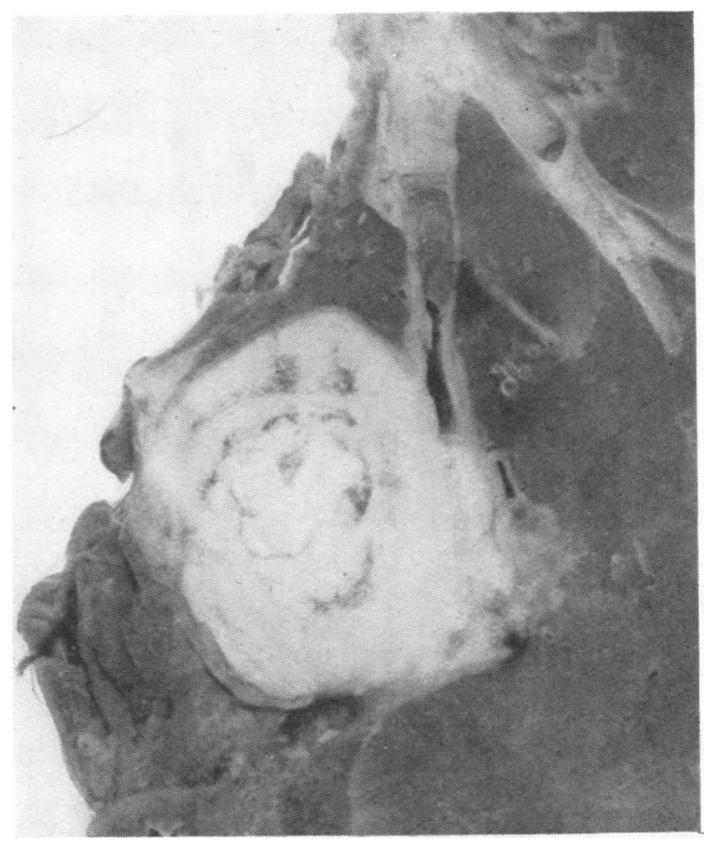

Fig. 13

Sputum cleared rapidly and the last positive stomach-wash culture was on January 2, 1951. By March the focus was only $1.5 \mathrm{~cm}$. in diameter. The change was most noticeable in the inner half, no cavitation being visible. Resection was decided upon, and a right upper lobectomy was performed on March 5, 1951, with uneventful convalescence (streptomycin 83 g.).

The upper lobe of the lung was examined. Beneath the pleura there was a well-circumscribed, ovoid lesion $1 \mathrm{~cm}$. at its greatest diameter. There was a central yellow mass surrounded by pale and pigmented laminae of fibrous structure. At the blunt inner end of the ovoid the lesion was in communication with a subsegmental bronchus. Here there was some excavation of the caseous material (Fig. 6).

Sections were made from both ends of the ovoid lesion. That from the smaller outer end showed a zone of tuberculous granulation tissue surrounding a necrotic core formed of ghosts of alveoli filled with cells inside a dense capsule of fibrous tissue. The appearance of the blunt inner end was different. The ghost structure conserved in the necrotic area was that of alternating tuberculous granulation and lamellar fibrous tissue. An eccentric area of loss of structure was present. In this zone excavation had begun. But only an occasional polymorph was seen in a series of sections. Acid-fast bacilli were present only in the amorphous zone of necrotic tissue.

A cavitated round focus with eccentric laminated growth.

Case 5.-M.S., a housewife aged 20, developed a lymphocytic pleural effusion following a stillbirth in 


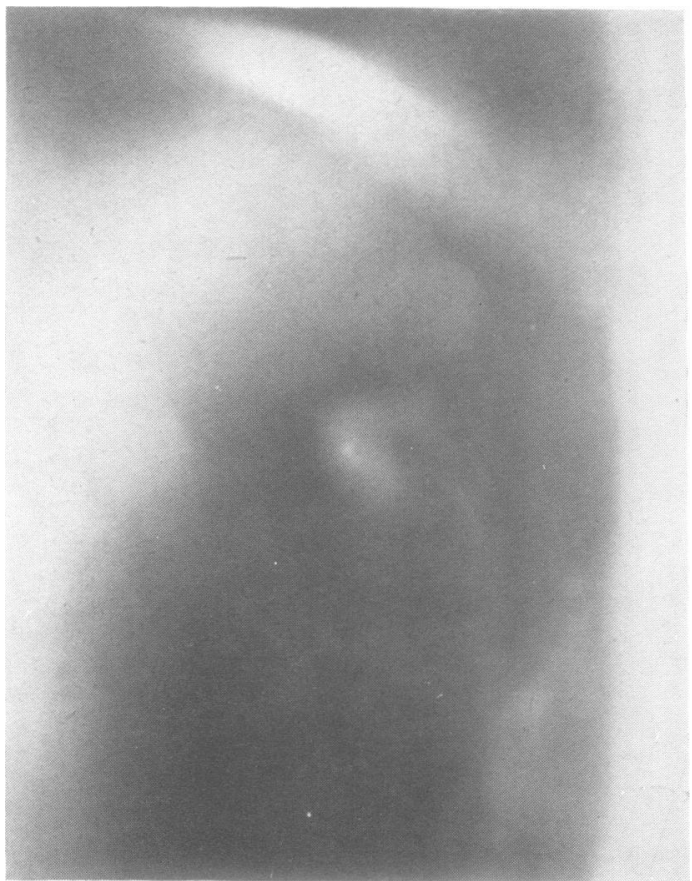

FIG. 14.-Tomographic section of Case 4 showing a $2 \mathrm{~cm}$.round focus The outer half is intact with a calcified centre. The inner half is cavitated and in communication with the bronchus. The related bronchi are outlined

July, 1946. She was first seen nine months later. She was symptom-free and a radiograph showed slight pleural reaction at the left base. She remained well apart from a trace of muco-purulent morning phlegm, which was negative on direct examination for $M$. tuberculosis. In June, 1948, a small focus, $1 \mathrm{~cm}$. in diameter, was noted in the extreme left apex. In August, 1948, a second focus was seen immediately adjacent and lateral to the first focus, being similar in size and density. In January. 1950, the centre of the innermost focus was denser, suggesting calcification. while at the same time a third focus had appeared, lateral to the two former. It showed in the first anterior interspace, and was of medium density and $2 \mathrm{~cm}$. in diameter. By October, 1950, the innermost lesion had become denser and smaller, but the third focus had enlarged to $2.5 \mathrm{~cm}$. with a suspicious pinhead central translucency (Fig. 15). By January, 1951. further calcification had occurred in the first focus. The second lesion remained unchanged, but the third had now developed a " pseudopodium." $0.75 \mathrm{~cm}$. wide. from its lower margin. The sedimentation rate throughout had been normal. Stomach-juice cultures were negative for $M$. tuberculosis. Apical and posterior segmental resection was carried out in February, 1951, with uneventful convalescence (streptomycin $22 \mathrm{~g}$.).

A segment of lung was examined. Beneath the pleura were three nodules, the medial $1 \mathrm{~cm}$., the middle $1 \mathrm{~cm}$. the lateral $2.0 \mathrm{~cm}$. in diameter. The lateral mass had a protruding small tongue of tissue similar to the main mass. All the nodules were alike $\overline{\frac{n}{}}$ Their centres were yellow with patchy black pigmen tation. They were surrounded by a thin greyis capsule and the lung intervening between the nodules? was collapsed and fibrous.

Microscopic examination showed that the three nodules consisted of a central zone of necrotic tissu $\vec{\omega}$ surrounded by a peripheral thin layer of fibrous tissug which contained lymphocytes and a few giant cells The structure was conserved in the necrotic tissue. but in each of the nodules the structure conserved wait different. The medial nodule showed the ghost of bronchopneumonia (Fig. 2). In one part there was $A$ focal loss of structure in which acid-fast bacilli werg present. The middle nodule showed the ghost of an organizing pneumonia surrounded by much fibrou tissue (Fig. 4). There was a focal loss of structure i⿱ which acid-fast bacilli were present in large number: The lateral nodule showed no alveolar structure. The ghost of an extensive granulation tissue mass wa seen (Fig. 1). An eccentric focus of loss of structure was present in which small numbers of acid-fast bacilg were seen. The segmental bronchus in this case showed evidence of tuberculosis.

Multiple round foci developing after a pleur(i⿱丶⿸⿰𠄌⿻コ一⿱丿丶㇀ effusion.

Case 6.- R.B., a housewife, was aged 23 in 194. when she was first known to have developed pulmon ary tuberculosis. A radiograph in January, 194. $\overrightarrow{0}$ showed extensive infiltration in the left upper lob with cavitation. Apart from the fact that the trans? verse interlobar fissure could be distinguished, the right iung was radiologically normal. She was treate by a left artificial pneumothorax induced in Jun 1945. This was maintained without incident until was successfully abandoned in June. 1949. The disease in the left lung now appeared to be well he:tle

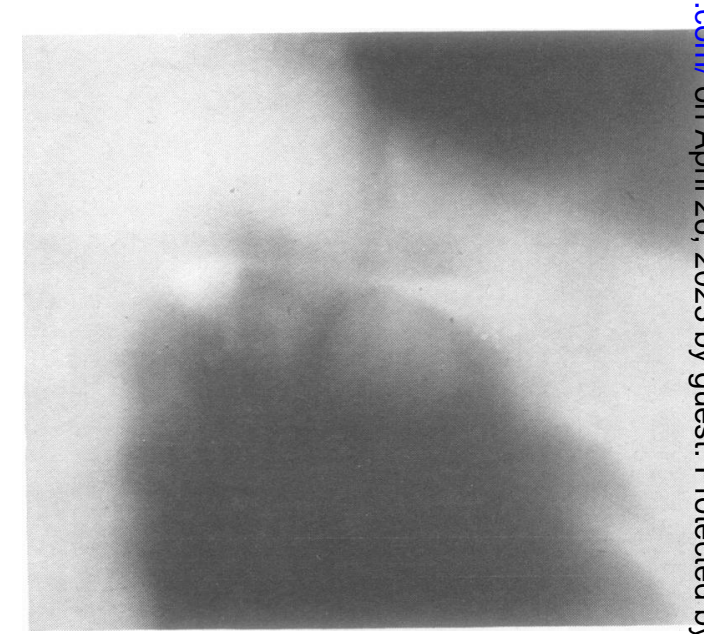

FIG. 15.-Tomographic section of Case 5 showing three round in the left apex. The innermost one is dense and calcified. outermost is the largest. $2.5 \mathrm{~cm}$. diameter. 
and no further comment on the disease on the left side is relevant. In February, 1946, the first focus was noted on the right side. There was a small $(0.5 \mathrm{~cm}$.) defined lesion radiologically astride the transverse fissure in the third right interspace. By November there was a much larger and ill-defined area of disease

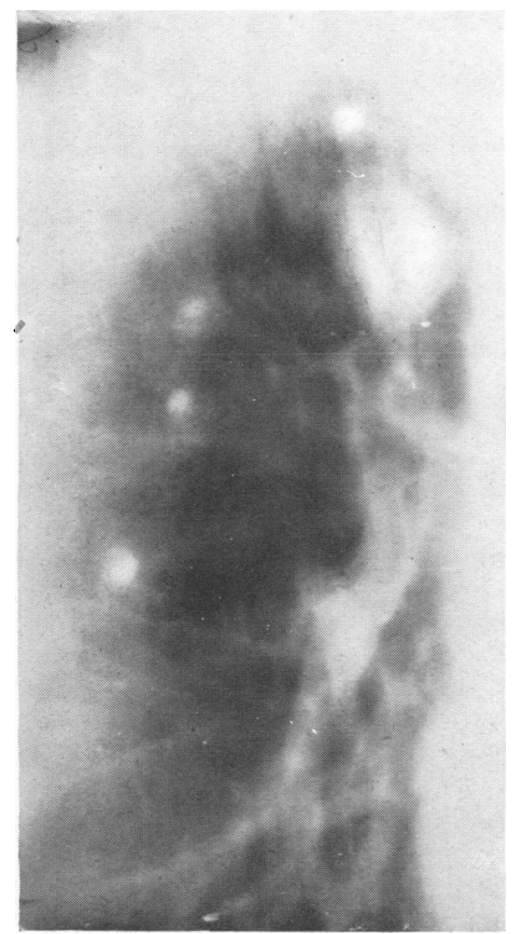

FIG. 16

in this region. In addition there was now some increase in the markings in the upper lobe, especially alongside the mediastinum. Directly under the first rib cartilage was a density difficult to define owing to the overlay of ribs. In February, 1947, there was a $2 \mathrm{~cm}$. tension cavity replacing the focus in the midzone. The lesion under the first rib cartilage was more easily seen, of medium density, $1.5 \mathrm{~cm}$. in diameter. The picture in June showed that the cavity had "blocked," being now opaque and $1.5 \mathrm{~cm}$. in diameter. The focus by the first rib had not enlarged and there were several flecks of calcium. Radiography in December, 1947, showed that the first rib focus had grown to nearly $2 \mathrm{~cm}$. in diameter. By September, 1948, the mid-zone focus remained unchanged. The upper round focus had further enlarged $2.5 \mathrm{~cm}$. in diameter with now a $0.5 \mathrm{~cm}$. central translucency. Scattered infiltration was evident in the supraclavicular region. Tomograms confirmed these lesions and suggested several small outlying lesions in the right upper lobe. The "comma" cavitation in the main lesion was well shown. The picture then remained unchanged, apart from slow growth of the main focus, so that by August, 1950 , it was over $3 \mathrm{~cm}$. in diameter

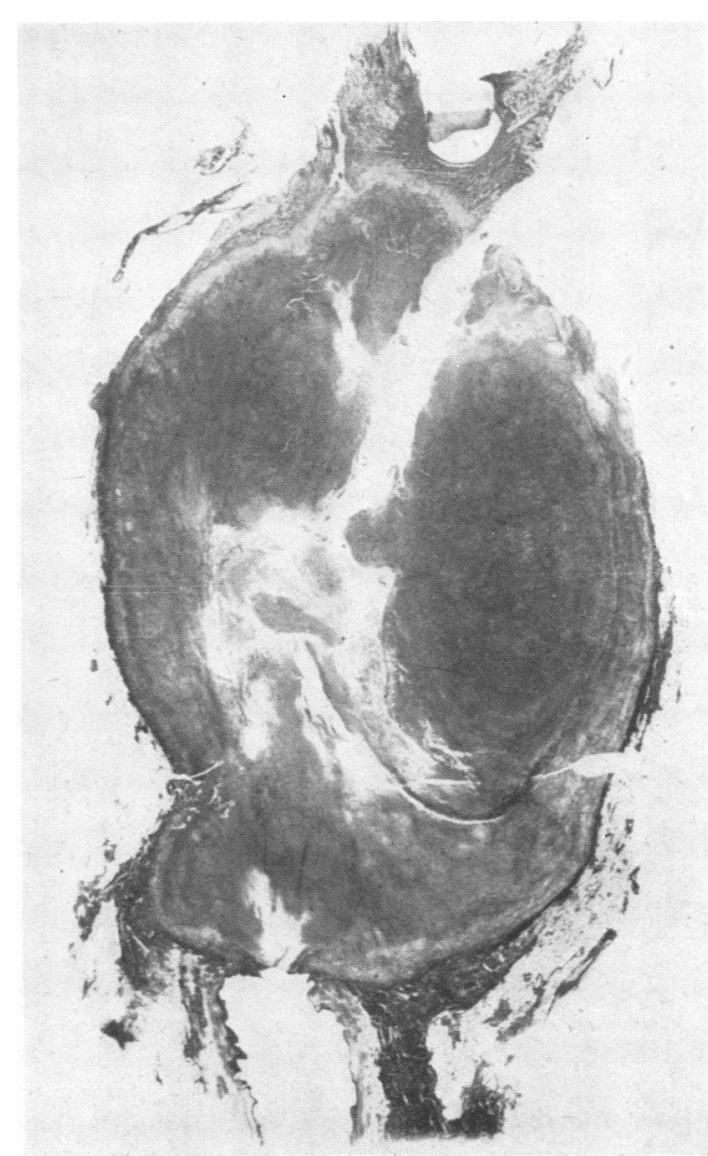

Fig. 17

with a $1.5 \mathrm{~cm}$. central translucency (Fig. 16). Bronchoscopy showed no evidence of bronchial tuberculosis. On October 22 the posterior segment was removed without difficulty. The mid-zone lesion was removed locally from the apex of the lower lobe. The immediate post-operative course was uneventful under streptomycin (total $30 \mathrm{~g}$.). The patient remained well until a further spread of the disease in the right upper lobe with positive sputum in March, 1951.

The specimen examined was the posterior segment of the lung. Associated with the segmental bronchus was a partly caseous ovoid yellow nodule $3 \mathrm{~cm}$. in its long axis, $2 \mathrm{~cm}$. in its short axis. The segmental bronchus was incorporated and destroyed in the edge of the lesion (Fig. 17). An irregular long narrow cavity had formed in the centre of the caseous material. The rest of the necrotic tissue presented an appearance of concentric laminae of thin pigmented zones and wider yellow zones (Fig. 18). Two small yellow outlying nodules were present. A second small piece of lung from the lower lobe contained a spherical, well-encapsulated mass of caseous material.

Microscopic examination showed a peripheral thin zone of fibrous tissue infiltrated with lymphocytes and 


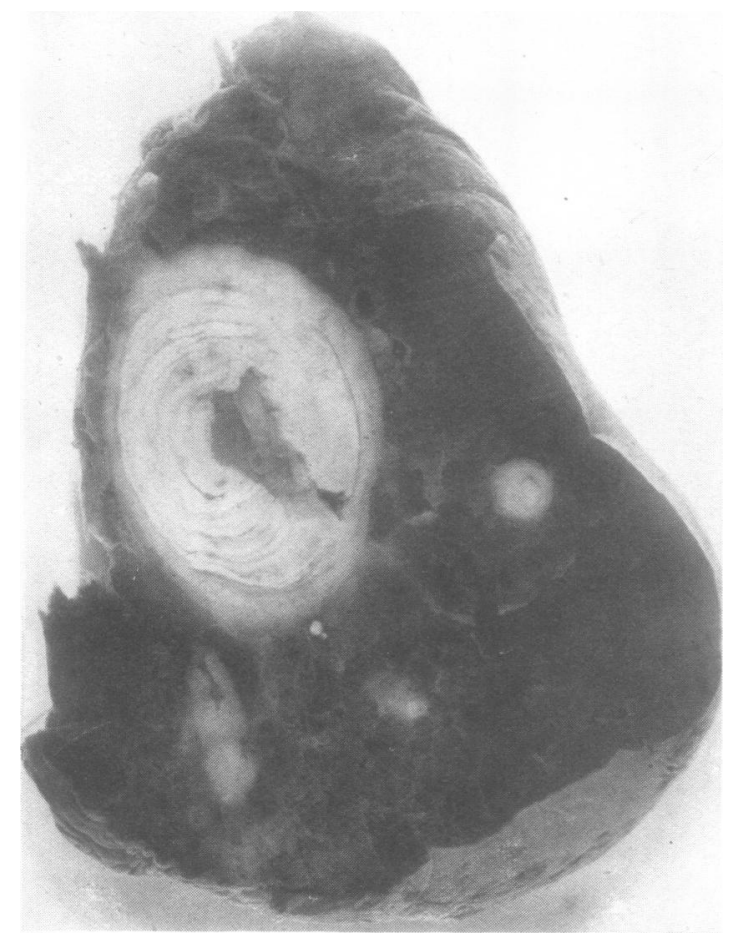

FIG. 18.--Pho:ograph of specimen of Case 6. The large round focus shows well its laminated nature with a liquefied centre. Two neighbourhood foci can be seen in addition to a section of a related bronchus.

with an occasional hard tubercle. Many similar noncaseous tubercles were present in the surrounding lung and bronchi. The central mass was necrotic, but its structure was largely conserved and demonstrated b; silver impregnation. It consisted of concentric zones of ghost tuberculous granulation tissue and pigmented lamellar fibrous tissue. The ceniral part was largely liquefied. but in the remairing parts showed the characteristics of a conglomeration of hard tubercles. Many polymorphs and eosinophil leucocytes were present in the liquefying parts. The nodule from the lower lobe consisted of amorphous caseous material containing many acid-fast bacilli encapsulated by a zone of dense fibrous tissue. The surrounding lung contained discrete hard tubercles.

A cavitated round laminated focus with accompanying fibro-caseous disease in the upper lobe. A typical "blocked cavity" in the apex of the lower lobe.

Case 7.-R.C. was aged 24 when first seen in July. 1943, with slight, right-sided chest pain. Radiography showed a small pleural effusion on the right side with slight mottling in the second and third right interspaces. In February, 1945, there was still some pleural change at the right base, but the lung field: were almost normal. A year later, January, 1946. there was massive infiltration in the right mid and lower zones. The main areat of consolidation was apparently in the upper part of the lower lobe, an cavitation was suspected. Stomach-wash culture $\frac{\bar{p}}{7}$ were positive for tubercle bacilli. By March consider $\mathbb{Q}$ able resolution had occurred and the main bulk of consolidation in the apex of the lower lobe was clearlis seen. By March, 1947, the right lung had clearecb further. Surrounded by mottling, the dense lesion in the apical segment was more defined, but on the P.A $\vec{\omega}$ film it was not recognizable as a round focus. Tomos grams in July, 1948. showed in addition to scattere $\overrightarrow{\vec{R}_{2}}$ foci one large dense hut not sharply outlined lesion in the apex of the right lower lobe with a small centralp $\mathrm{V}$-shaped translucency. Radiography in January $\underset{\omega}{\omega}$ 1949. showed an increase in the size of the main focus and by June. 1949. there was further growth. The focus was well outlined on tomography, 4.5 by $3.5 \mathrm{~cm} .+$ with now a large Z-shaped cavity (Fig. 19). In September. 1949. the right lower and middle lobe: were resected under streptomycin (total 82 g.). ThS post-operative course was uneventful and sho remained well until July, 1951. Radiography at thi time showed that further disease had developed ir $\overrightarrow{0}$ the remaining lobe.

At the apex of the lower lobe of the lung was : mass $3 \mathrm{~cm}$. in diameter. The central part of the maso had undergone cavitation, the middle zone was caseous, and the periphery was dense and fibrous. No obvious communication existed between the centre of this mass and the superior and inferior branches o the apical bronchus. These were, however, partl incorporated in the periphery of the mass. Lamina응 tion was not well marked except at the periphery of the lesion. The whole mass was irregularly mottled

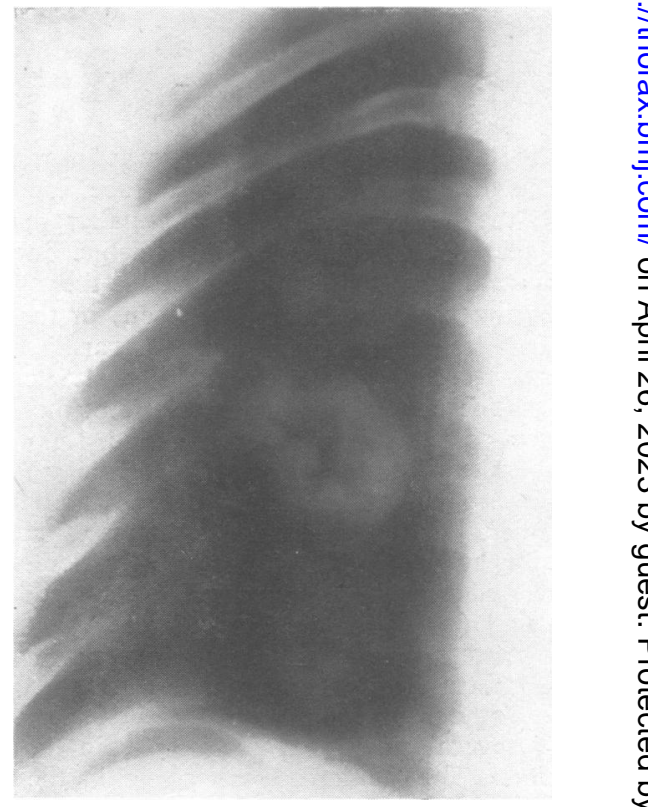

Iic; 19. - Tomographic section (Case 7) of the round focus in th apex of the right lower lobe. The large $Z$-shaped cavity is welo seen. 


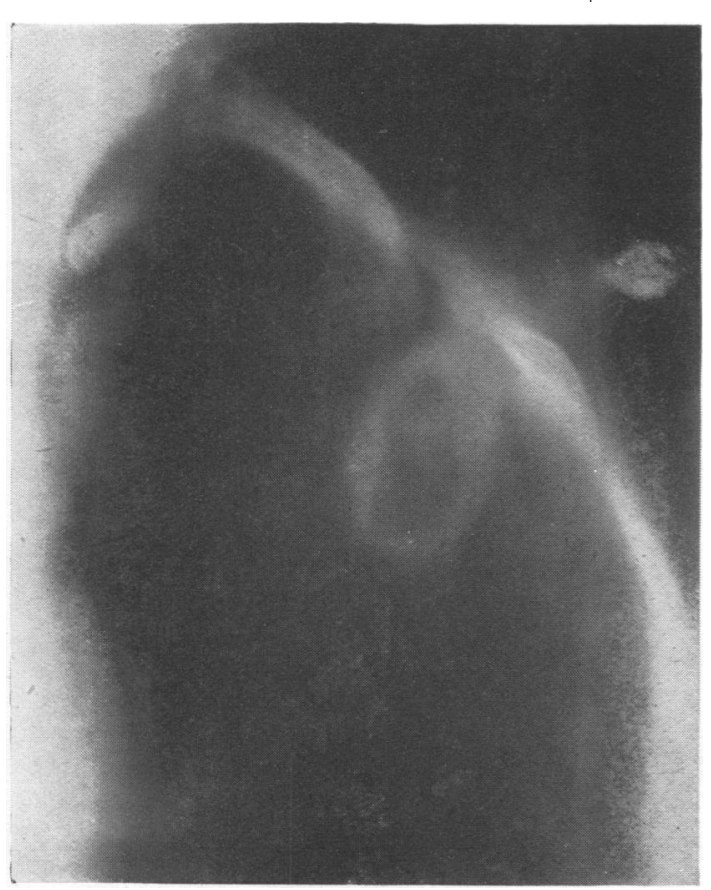

FIG. 20.-Tomographic section of Case 8 in October, 1950, showing a large cavity in the left upper lobe.

with pigment. Scattered throughout the rest of the lung were small nodules of hard caseous material up to $0.5 \mathrm{~cm}$. in diameter, firmly encapsulated by black, hard, fibrous tissue.

Microscopic examination showed a necrotic, partly liquefied mass surrounded by a wide spreading zone of non-caseating tubercles. Similar discrete tubercles were scattered in the surrounding lung. The necrotic mass had its structure partly conserved. This showed the ghost of tuberculous granulation tissue.

A laminated round focus which developed and cavitated in a lobe extensively involved by fibrocaseous disease.

Case 8.-M.P. was a housewife aged 29. In July, 1949 , a mass miniature radiograph showed infiltration in the left upper lobe. She was symptom-free. Her picture in October, 1950, showed that the lesion had cavitated (Fig. 20), the main focus, 5 by $3 \mathrm{~cm}$., showing a 3 by $2 \mathrm{~cm}$. translucency. She was treated by streptomycin (42 g.). By April, 1951, the lesion was smaller and the cavity had "blocked" (Fig. 21). Resection was decided upon and performed on May 8 under streptomycin (a further total of $63 \mathrm{~g}$.). The post-operative course was smooth apart from a slight fever for six weeks.

A segment of the left lung was examined. There was a large caseous mass, $3 \mathrm{~cm}$. in diameter, associated with the segmental bronchus, which was deformed and apparently occluded by fibro-caseous tissue. The caseous mass was mottled with black pigment, and the central core surrounded by grey fibrous tissue. The adjacent lung was collapsed and contained many fibrocaseous foci.

Microscopic examination showed a central caseous amorphous mass surrounded by a broad zone of fibrocaseous tuberculous tissue. The adjacent lung contained many small fibro-caseous foci. Large numbers of acid-fast bacilli were present in the caseous material.

A "blocked" cavity in an area of fibro-caseous disease.

Case 9.-N.M., a housewife, was aged 28 in 1939 when she developed a small, left-sided pleural effusion. In January, 1941, radiography showed a rounded shadow, $1 \mathrm{~cm}$. in diameter, underlying the first left costal cartilage. In October, 1943, her sputum was positive for $M$. tuberculosis, and radiography showed that in the place of the round focus noted nearly three years previously there was a $3 \mathrm{~cm}$. round focus, with a small central translucency. Overlying the second left space was a new cluster of three or four round foci each about $1 \mathrm{~cm}$. in diameter (Fig. 22). By December, 1944, the focus had increased to $3.25 \mathrm{~cm}$. She had had no treatment for her chest disease, nor was there any precise episode of illness or incapacity during the interval until the next radiograph in March, 1946. This picture showed a decrease in the size and definition of the large focus (approximately $2 \mathrm{~cm}$. in diameter). By December, 1947, the large focus could not be distinguished, the site showing linear streaking into the hilum only. The foci in the cluster were also smaller and harder with flecks of calcification (Fig. 23).

Multiple round foci, developing after a pleural effusion. The largest focus clears after being $3 \mathrm{~cm}$. in diameter.

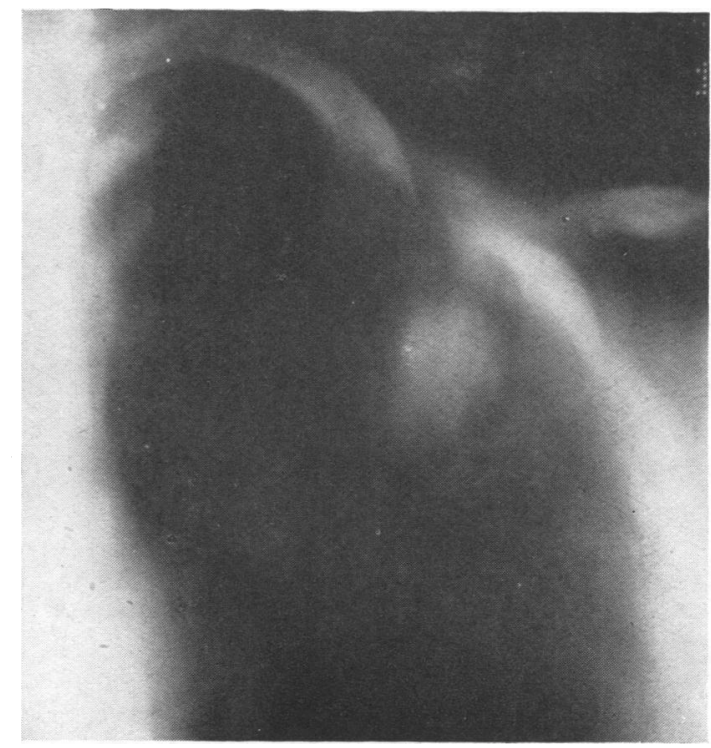

FIG. 21.--Case 8. Tomographic section of Case 8 showing the lesion to be smaller; cavitation is not visib!e Blocked cavity. 
Fig. 22

Fig. 23.--Radiograph in December, 1947. The large round focus has been replaced by a linear scar. The cluster in the second left interspace is more easily seen.

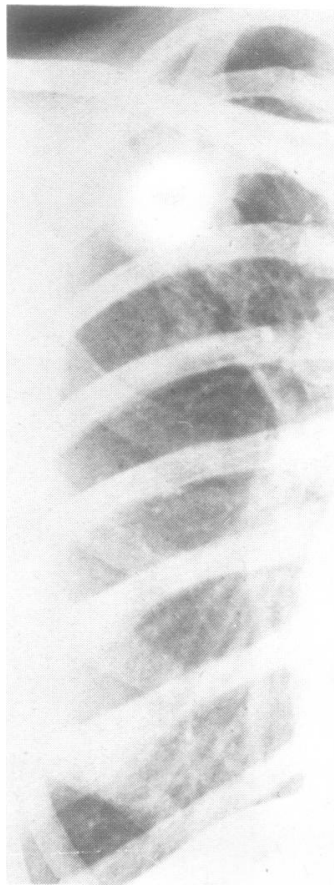

FIG. 26
FIG. 25
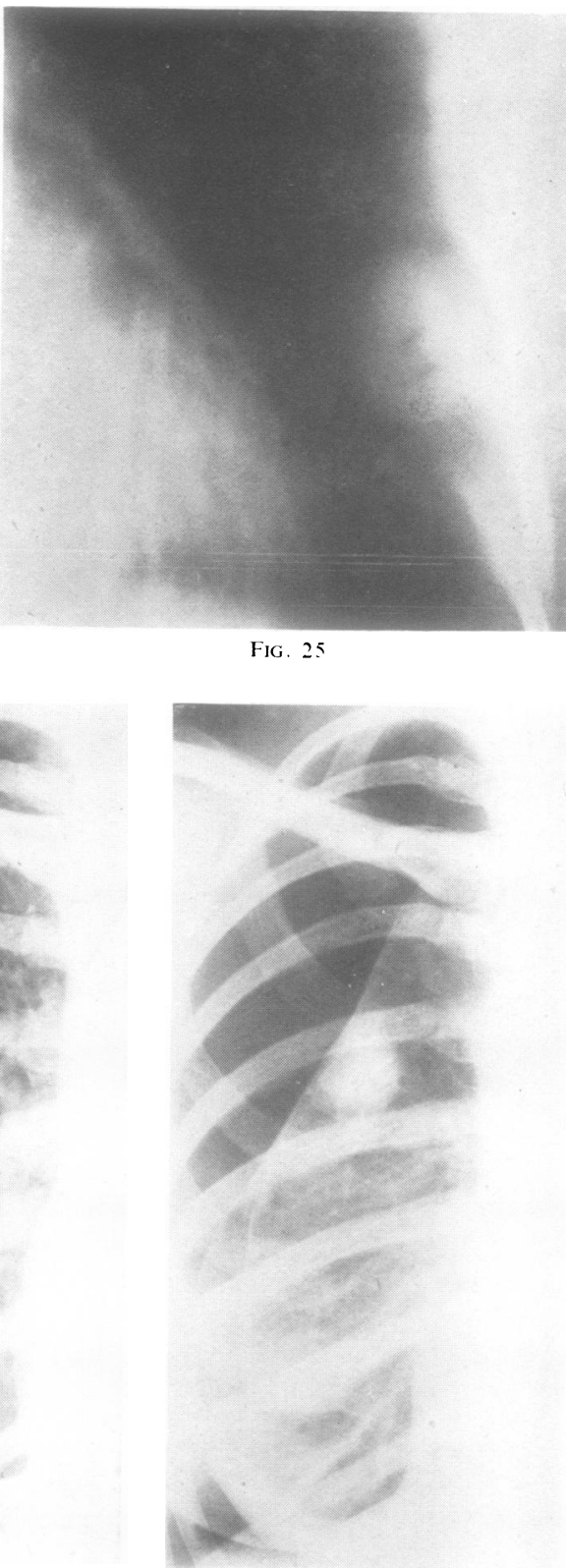

FIG. 27

Flg. 24.-Tomographic section of Case 10 showing a $1 \mathrm{~cm}$. round focus in the right upper lobe with associated infiltration.

FIG. 25-Tomographic section of Case 11 showing a large round focus, probably in the lingula. The central translucencies can be seen.

FIG. 26. - Radiograph of Casc 12 in May, 1945, showing a large round focus in the right upper lobe with central cavitation. There is some accompanying infiltration.

FIG. 27. - Radiograph of Case 12 in May, 1946. A pneumothorax is present. The round focus can still be seen in the right upper 
Case 10.-J.P.R., a student aged 22, in November, 1947 , coughed up a small trace of blood. On admission his picture showed infiltration in the right upper lobe. No cavitation was demonstrable on tomography, but a $1.5 \mathrm{~cm}$. bean-shaped focus was noticed (Fig. 24) in the outer part of the first interspace. Cultures were negative for $M$. tuberculosis. An artificial pneumothorax was induced in January, 1948. The round focus was well seen at the start of treatment, but by June it was very much smaller (under $1 \mathrm{~cm}$. in diameter) and by March, 1949, it was converted into a linear scar. The accompanying infiltration had also improved.

Round focus with accompanying fibro-caseous disease, resolves satisfactorily under artificial pneumothorax.

Case 11.-J.E. was a clerk. In February, 1944, when aged 18 , a routine radiograph showed a small area of infiltration in the left upper lobe. This cleared, and her picture in August, 1944, was almost normal. She was a big girl and large breast shadows tended to obscure the basal regions. In June, 1945, a diffuse area of shadowing appeared external to the heart border in the left fourth and fifth spaces. The shadowing persisted almost unchanged until January, 1946. It was then clear that the upper part of this opacity was formed by a round focus $3.5 \mathrm{~cm}$. in diameter. It appeared to be in the lingula. The focus was identified further by tomography, showing in its centre two small " comma" translucencies (Fig. 25). Sputum was positive on culture for $M$. tuberculosis. In February, 1946. a left artificial pneumothorax was induced successfully. Within the first year of treatment the focus had shrunk to about $3 \mathrm{~cm}$. By May, 1948 , it had decreased further to $2 \mathrm{~cm}$. in diameter, but it was difficult to see clearly in the postero-anterior view. The pneumothorax was then abandoned. A year later the lung picture was almost normal. She was well when last seen in October, 1950.

A large and cavitated round focus which resolves satisfactorily under a pneumothorax.

Case 12.-V.W., a munition worker, was aged 20 when she first attended St. Thomas's Hospital as a contact of her uncle, who had open pulmonary tuberculosis. She admitted to having a smoker's cough for six months. Radiography in May, 1945, showed a large rounded density $3.5 \mathrm{~cm}$. in diameter, with a $1 \mathrm{~cm}$. central translucency in the right upper lobe (Fig. 26). A right artificial pneumothorax was induced in July, 1945. A year later, in May, 1946, radiography showed a reasonable selective pneumothorax. A $2 \mathrm{~cm}$. rounded focus was easily seen in the right upper lobe. There was a small effusion (Fig. 27). By August, 1948, the round focus had been replaced by dense linear scars with intermingled flecks of calcification.

A round cavitated focus which responded well to artificial pneumothorax, the cavity closing early and eventually healing by scar tissue.
Case 13.-M.G., a waiter aged 23, coughed up some blood in December, 1948. Radiography in January, 1949, showed infiltration in both upper lobes. On the left it was above the first rib and mottled in character. On the right the disease was more extensive, extending down to the second space. A round $1 \mathrm{~cm}$. focus was well seen in the first space, with a dense $0.5 \mathrm{~cm}$. nucleus of calcification. Radiography in March, 1950, showed in the first right interspace a roundish lesion, apparently in close relation to the focus mentioned above. It was $2.5 \mathrm{~cm}$. in diameter. On the left side a new, small $0.75 \mathrm{~cm}$. round focus was also visible in the first interspace. These changes were confirmed by tomograms in May, 1950 (Fig. 28). This examination also showed additional round foci in both upper lobes.

Multiple bilateral and round foci, some calcifying, some enlarging.

Case 14.-D.S., a technician, was aged 24 in 1946 when he was found to have a right tuberculous kidney, which was removed. A chest radiograph at this time was reported as normal. A routine picture at his work in 1950 showed infiltration in both upper lobes and also a rounded lesion in the anterior part of the right middle lobe $3 \mathrm{~cm}$. in diameter (Fig. 29). Sputum culture was negative, the E.S.R. normal, and the Mantoux reaction positive $1 / 1,000$.

Bilateral upper lobe fibro-caseous disease with a large round focus in the middle lobe. Type unknown.

\section{Discussion}

The lesions we have seen fall into two categories. In the first the lesions are a stage in the history of a cavity where the draining bronchus has become occluded, the air absorbed, and the walls contracted about the remaining caseous contents. This phenomenon may or may not be associated with at least temporary limitation of the disease. In one of our examples the disease was clearly progressive, the surrounding lung showing active fibro-caseous tuberculosis (Case 8). In another (the small lesion in Case 6) there was radiological evidence of the conversion of a small cavity into an apparently quiescent solid nodule, which on microscopic examination was found to be well encapsulated by fibrous tissue. But the presence of large numbers of acid-fast bacilli in the mass belied its inactive appearance. This process has been well described in the literature (Auerbach and Green, 1940 ; Pagel and Simmonds, 1942 ; Loesch, 1944). In the second category are those lesions in which masses of tissue are sealed from the outset of the disease process and through the greater part of their life history show less tendency to undergo the extensive softening and cavitation which is the fate of many tuberculous lesions in the lung. These masses consist usually 

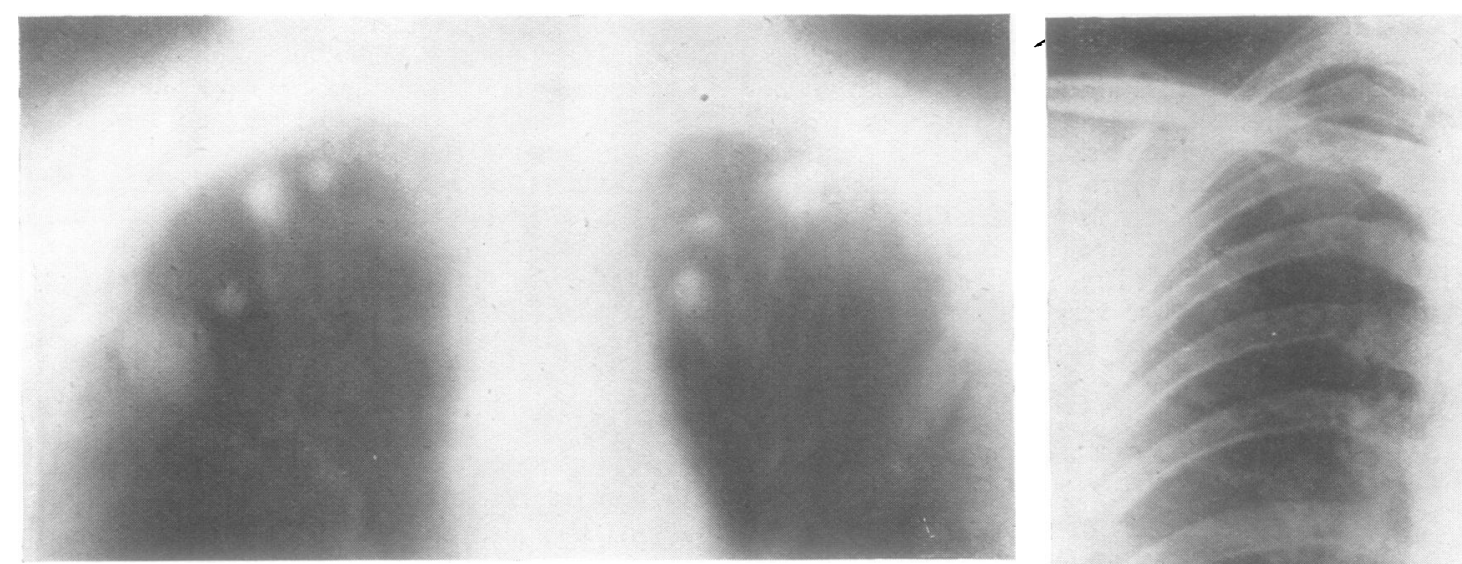

FIG. 28

of a central core of pneumonic consolidation or of a small conglomeration of hard tubercles about which are arranged laminae of tuberculous granulation tissue and of lamellar fibrous tissue in succession. These layers evidently represent successive phases of activity and relative quiescence in the life of the lesion as it gradually increases in size from within outwards. The secondary phenomena of pigmentation, especially in the lamellar fibrous tissue, and of calcification in the central focus and in the cellular layers make the laminated structure obvious to the naked eye. In our cases we found the greater part of the solid masses necrotic, but in two examples (Cases 3 and 4) a considerable amount of live tissue was present at the periphery of the lesions which were clearly in a state of active growth. In the greater part of the necrotic tissue the structure was found to be conserved. To the naked eye this tissue was creamcoloured and to the touch it preserved its elasticity. Small central parts of necrotic tissue were caseous, that is, they were light yellow, had the consistency of soft putty, and on microscopic examination no structure was seen to be conserved.

In all of the sections examined it was remarkable that tubercle bacilli were absent in those parts where the structure of the necrotic tissue was conserved, but that there were very many in the middle of the amorphous mass. The underlying basis of the transformation of necrotic tuberculous tissue through the stages of caseation and liquefaction are quite obscure. The matter has been discussed at some length by Rich (1944). Neither infiltration by polymorphs nor secondary infection will serve to explain the changes, although the former must be of considerable importance when once excavation has taken place into the bronchus. In one of the largest examples (Case 3) lique-

FiG. 28.-Tomographic section of Case 13 showing round foci in both upper lobes Some are dense and calcifying ; others, notably the most lateral focus on the right, are growing.

FIG. 29.-Radiograph of Case 14. There are a few scattered infiltrative lesions in the upper lobe. A large round focus, situated anteriorly in the middle lobe, is masked by the normal lung markings and can only just be distinguished.

faction had occurred in the centre of the caseouș. mass. There was no bronchial communication with the liquefied tissue, which consisted of small amount of milky fluid. Neither were any secondary infecting organisms nor any infiltratings leucocytes demonstrated. In two other lesions. (Cases 4 and 6), which had liquefied, a bronchia communication was established with the cavity formed. In neither was gross secondary infectiors present, but in one (Case 6) extensive poly $\rightarrow$ morph infiltration of the caseous material was. seen. In the other (Case 4) there was only añ occasional polymorph.

On account of the way in which the fibres con served in the necrotic tissue had been abruptlow disintegrated and because some of the caseous areas were eccentrically placed, it seemed more - likely that caseation and liquefaction occurreș subsequent to the necrosis of the main mass rather than that the granulation tissue had developed about the central caseous focus and had undergon necrosis at a later date.

It may be stated then that these lesions are the result of progressive but fluctuating centrifuga $\bar{P}$ growth of tuberculous granulation tissue whiclo 


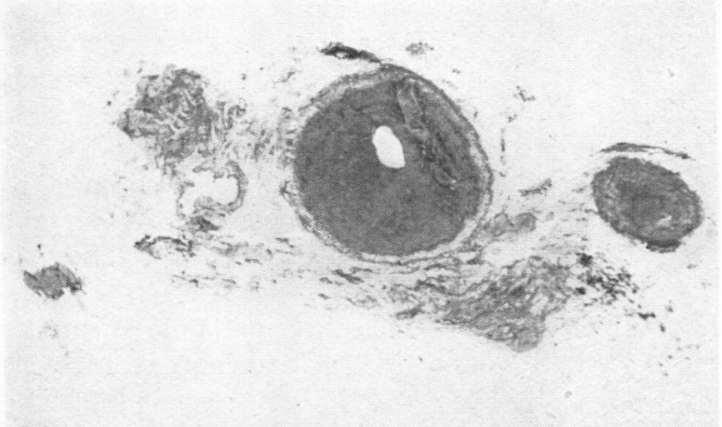

FIG. 30.-Section (Case 6) showing a satellite nodule. The central hole is the lumen of a bronchus.

undergoes necrosis and may become caseous or even liquefied. The factors responsible for these changes are largely unknown. This category of round foci resembles the lesion seen in the brain and meninges and usually referred to as a tuberculoma. The lesion in brain was described by Virchow (1858), who pointed out that the rounded mass was a collection of thousands of small tubercles. We have not seen the lamination which is characteristic of the larger lung lesions in the tuberculomata of the brain, but in the museum at

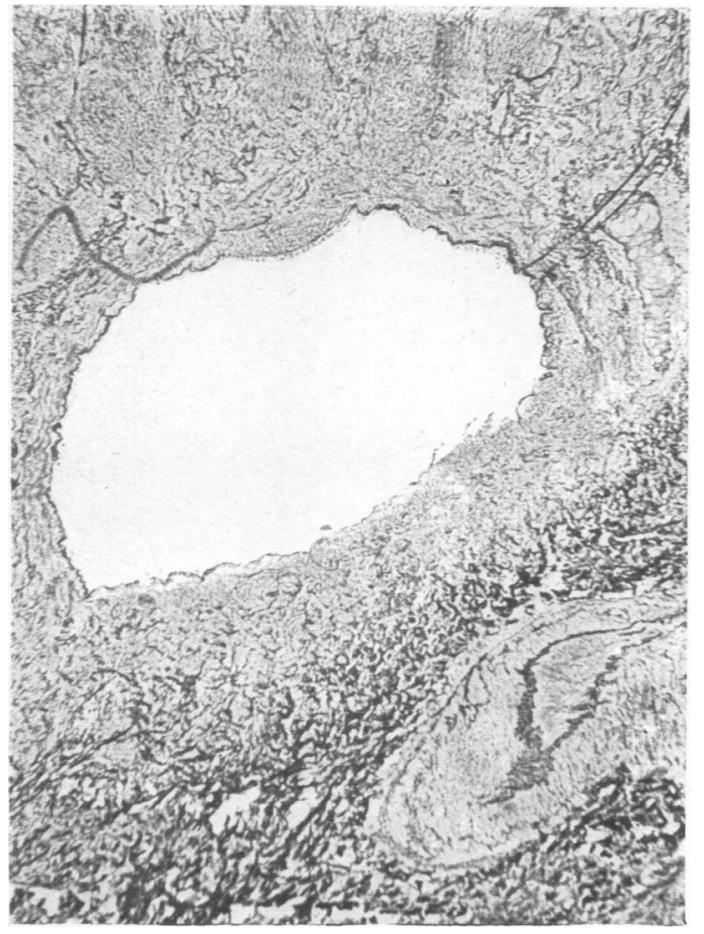

FIG. 31. A higher magnification of the centre of the satellite nodule in Fig. 30. Silver impregnation shows the structure of the bronchus, alveoli, and pulmonary artery in the necrotic tissue.
St. Thomas's Hospital is a specimen (6B.6.4) of a large tuberculoma of the dura in which the concentric laminated arrangement, without the pigmentation, is clearly visible. In microscopic sections taken both from this specimen and from a tuberculoma of the brain (6A.6.2) ghost structure of granulation tissue is clearly seen by indirect illumination and demonstrated by silver impregnation in the necrotic part of the mass. The non-laminated mass had probably increased in size by a process of continuous steady growth of granulation tissue, the laminated one by a rise and fall in activity from time to time. These observations are not in accord with the general belief that necrosis in tuberculosis results in rapid loss of structure, whereas in syphilis the structure of pre-existing granulation tissue is conserved when necrosis occurs (Biggart, 1936). It may be that in these brain and lung lesions the underlying basis of necrosis in which the granulation tissue structure is conserved is the same as that believed to operate in syphilis, namely, ischaemia as a result of occlusive changes in the vessels of the part. We have not been able to make any observations bearing on this point in the lungs we have examined, but in a small tuberculoma of the brain from a child the blood vessels lying in a conglomerate mass of small tubercles showed a great degree of intimal hyperplasia, and endarteritis of the meningeal vessels in tuberculous meningitis has long been recognized as an important factor in that disease.

The relation of the relevant bronchus to tuberculous lesions in the lung is always very important. In our second category of cases the involvement of the bronchus has, we believe, been a secondary phenomenon. The tuberculous mass has grown until it has impinged on a segmental or subsegmental bronchus. The wall has been infiltrated and destroyed and the continuity of the lumen lost. Bronchial epithelium may grow over the granulation tissue where it occludes the lumen, converting it into a cul-de-sac (Fig. 17), both on the distal and on the proximal side of the lesion. The bronchus is thus eccentrically placed in relation to the lesion and in Case 3 (Fig. 13) its position was almost tangential. In one case, however, the bronchus had a special relation to the centre of the lesion. This was in a satellite nodule $0.75 \mathrm{~cm}$. in diameter (Case 6, Fig. 30). Here the central focus was evidently in the bronchus itself and in the surrounding lung alveoli resembling some of the lesions described by Klein and Wolff (1934). The central nezrotic part of the focus had the structure of bronchus and of pulmonary artery well conserved (Fig. 31), but there was no disten- 


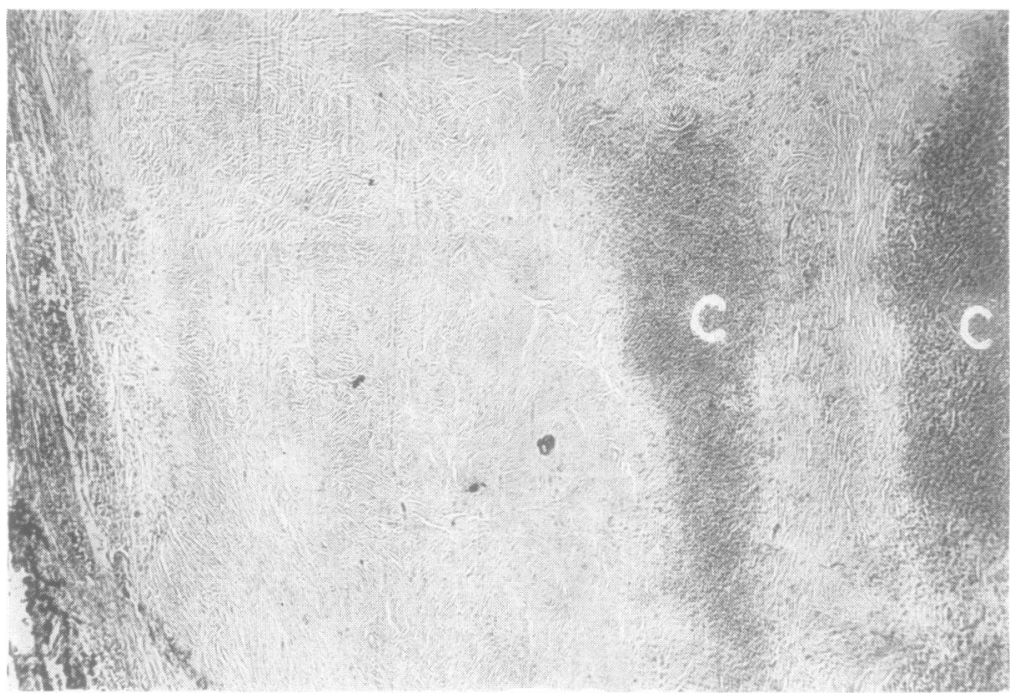

Fig. 32. - Section (Case 1), stained with haematoxylin and eosin, showing anparently structureless necrotic mass. At $C$ are laminae of calcification.

reaction is deposited in strata separated by clear intervals " (Burns, 1921). The strata are $\vec{\nabla}$ densest and closest nearest to the interface between the gelos and the reacting solution. and $\overrightarrow{0}$ tend to be spaced wider and $\overrightarrow{\vec{H}}$ wider apart in proportion to the distance from the inter $-\overrightarrow{\vec{F}}$ face. It would be surprising. if this phenomenon were really the basis of calcifi- $\omega_{\omega}^{\omega}$ cation in our lesions, for in these the densest zone of cal-음 cification is in the centralpart, and often there has been no calcification in the most peripheral laminae of 3 necrotic tissue. It seems@ clear that the successive $\overrightarrow{0}$ layers of granulation tissue N have grown, died, and calci-

sion of the bronchus by accumulation of tissue and debris within it. nor was the lesion confined to the bronchus as in Brock's case (1946).

Tuberculomata of the bronchus have been described by several authors (Benda, Franchel. Arnaud, and Andreety, 1949: Epstein and Ornstein, 1936; Moretti and Verdeau, 1949). The lesions reported are intrabronchial growths of granulation tissue, sometimes polypoid and covered by epithelium. Their development would appear to be entirely different to the foci described above. Further, their clinical and radiological features are those of partial or complete bronchial block with obstructive inflation or atelectasis. Kerley's (1951a) radiological observations are interesting on this account. He had noted the sudden appearance of round foci at the inner apex of shadows interpreted as areas of atelectasis. $\mathrm{He}$ does not report any pathological study.

One of the outstanding factors in our cases has been the concentric spheres of calcification within the necrotic mass. This calcification has been demonstrated to lie in the broad laminae between the thin pigmented layer (Fig. 32). In one of our examples (Case 2) this was just observable on the radiograph. In the case published by Haight and Farris (1939) the laminae are remarkably well seen. The existence of concentric rings of calcification in tuberculous lesions is said (Pagel, 1948a) to be an example of the Liesegang phenomenon: "If a gel contains a substance in solution and a second substance capable of reacting with the first is allowed to diffuse into the gel, the product of the fied. Subsequent concentric layers of calcification are formed merely by conditions of new granulation tissue which dies and calcifies in the same way.

Whether these lesions are primary or post- $\stackrel{\mathbb{Q}}{2}$ primary we cannot tell. There are no histologi- $\overrightarrow{0}$ cal criteria which can certainly differentiate the 3 primary and the post-primary lesion. Only on the presence of caseous lymph glands related to the focus can any reliance be placed, and in this matter our information is wanting. Nassau and Pagel (1951) have recently described specimens removed at operation which are probably similar to ours. They found round solid foci both as. primary and as post-primary lesions, and it is pro- 0 bable that our cases represent both primary and post-primary lesions.

Several authors have suggested that round foci may develop in the lung through the confluence of several smaller areas of infiltration. The develop-N ment of such conglomerates has been suggested by radiological observation over several years (Galy, 옹 Bérard, and Dumarest, 1948 ; Mahon and Forsee. $\omega$ 1950 ) or by the appearances of the focus on tomography (Sellors and Hickey, 1949). Mahon ando Forsee state that this lesion microscopically is formed by a fusion of small units of encapsulated $\stackrel{\mathscr{P}}{+}$ lobular caseous pneumonia. None of our cases showed or suggested such a formation. Gerhartz, who described a radiological round focus in 1915, postulated that round foci, especially when $\mathbb{\complement}$ multiple, are representative of tuberculous intra-O pulmonary lymph nodes (Gerhartz, 1932). The 


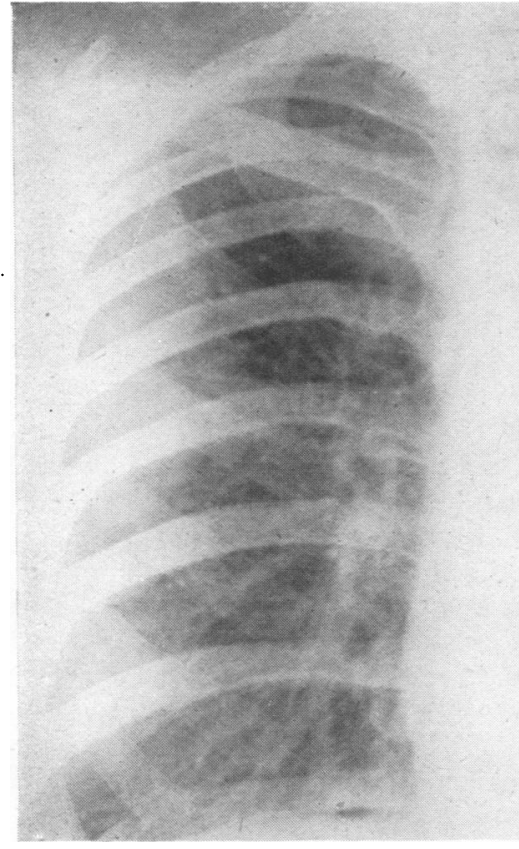

Fig. 33
FIG. 33.-Radiograph in June, 1951, showing an oval area of consolidation in the axillary part of the right upper lobe.

FIG. 34. -Tomographic section of the consolidation in Case 15 showing its formation by three main encapsulated foci with infiltration around the bronchi towards the hilum.

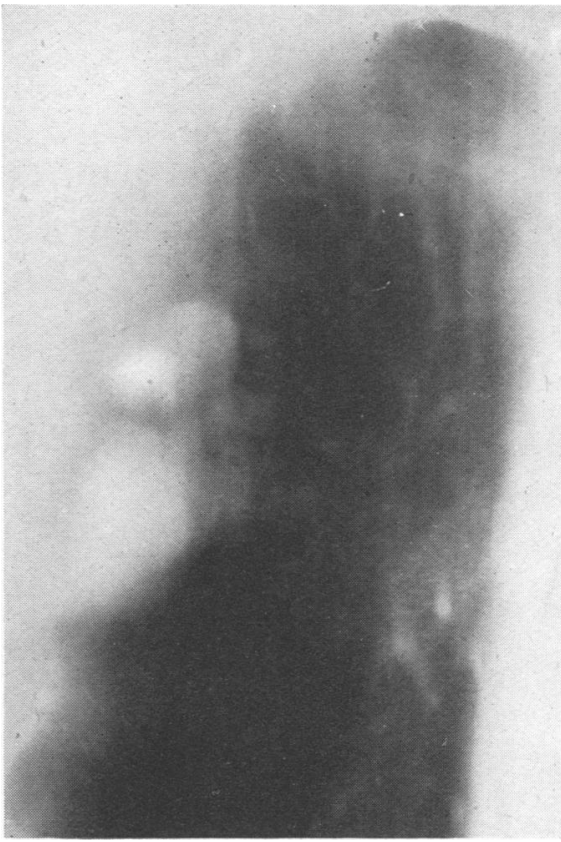

Fig. 34 cluster of dense rounded shadows characteristic of gross hilar adenopathy is well known, but there does not seem to be any support for the contention that the more peripheral round foci are also glandular in origin.

In our specimens the central ghost-like area of pneumonia has been a small one (less than $1 \mathrm{~cm}$. in diameter). However, larger areas of tuberculous consolidation may be encapsulated. For example, primary foci may be, as Küss noted (1898), " as large as a hazel nut," or even as big as a tangerine (Pagel, 1948b). The fibrotic envelopment of large caseous areas is a well-recognized feature of advanced phthisis. The following case is of interest in considering the sealing-off of large areas of caseous pneumonia.

Case 15.-A.H., a student, was aged 23 when first seen in March, 1950. In the previous August his father was found to have developed pulmonary tuberculosis. A.H. was radiographed at the time and the picture was reported as normal. In September, 1949, he had "flu." In March, 1950, he was referred to St. Thomas's Hospital, where a radiograph showed on the right side some irregular shadowing over the inner part of the second interspace, adjacent but lateral to the upper hilar shadow. The transverse fissure was also identifiable. On review a small focus at the periphery, in the third space, could also be seen. The Mantoux test was positive $1 / 10,000$. It was considered that this lesion was probably tuberculous and might well be a primary complex, possibly arising with the "flu" in the previous September. He was rested at home with no specified treatment. By July the main shadowing had apparently cleared. A slight peripheral mottling in the third and fourth spaces, partly fused with the scapular shadow, was not noted at the time. In September, 1950, he had a very severe cold with some yellowish sputum. When seen in January, 1951, he was again free of symptoms. A radiograph now showed a roughly oval diffuse shadow 8 by $4 \mathrm{~cm}$. overlying the second, third, and fourth spaces on the right (Fig. 33). The appearances were consistent with consolidation, and it was considered that he now had a tuberculous consolidation mainly in the axillary part of the posterior segment of the right upper lobe. He was treated in bed at home pending admission. Streptomycin had to be abandoned at the time owing to bizarre symptoms, suggested to him by "what he had heard" about the drug. He remained symptomfree, gaining overweight. His picture showed surprisingly very little change, suggesting the indolence of "epituberculous" consolidation but without its definition. Radiographs in May and June suggested a "rounding-off" of the upper and lower margins of this area of consolidation. The shadow was assuming the character of a vertical oval 8 by $5 \mathrm{~cm}$. with a medial streaking towards the hilum. The interpretation was clarified by tomograms in July (Fig. 34). They showed that the picture was a composite one. It was built up by at least three large defined foci, $2 \mathrm{~cm}$., $2.5 \mathrm{~cm}$., and $3 \mathrm{~cm}$. in diameter respectively, with smaller foci and mottling narrowing down to the hilar region. In view of the massive nature of the foci and their slowness to resolve it was considered proper to 


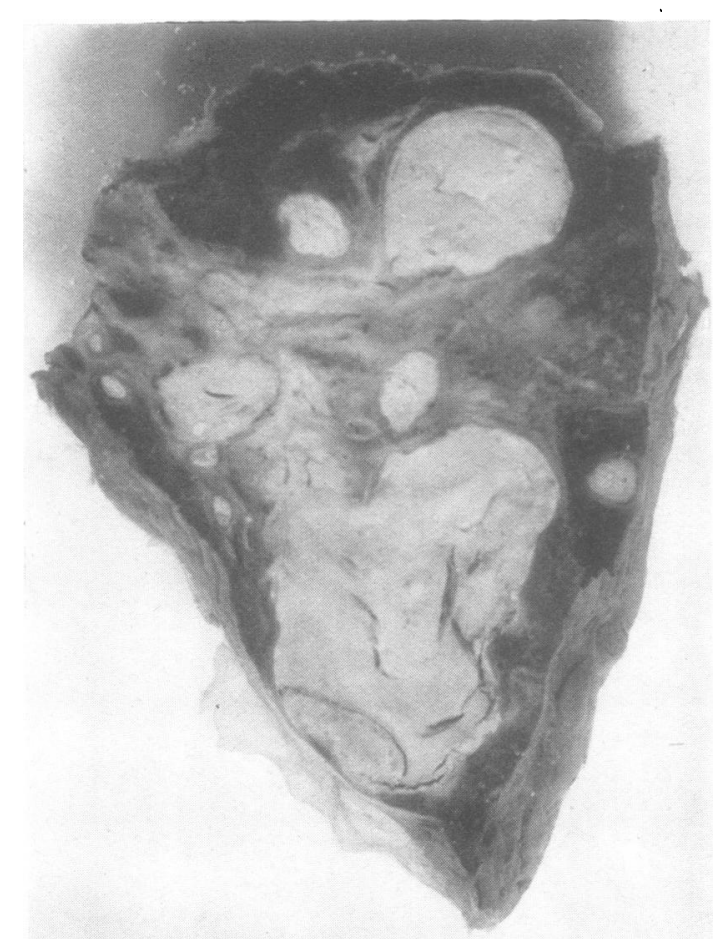

FIG. 35.-Specimen (Case 15) showing the unexcavated gelatinous caseous lesions, the caseous bronchi, and the tiny, subpleural, well-encapsulated lesion.

remove them. A segmental resection was carried out without incident on August 13, 1951. He was given $100 \mathrm{~g}$. of streptomycin and convalescence was uneventful.

The specimen examined was a segment of lung in which there were three large and at least four smaller lesions (Fig. 35). The three largest were respectively $3.5 \mathrm{~cm}$., $2 \mathrm{~cm}$., and $2 \mathrm{~cm}$. in diameter. These lesions all presented a similar appearance. A central yellow, somewhat gelatinous mass was surrounded by a thin zone of greyish fibrous tissue which demarcated it from the surrounding lung. There was no excavation of the lesions. The branches of the segmental bronchus were caseous.

One tiny $(0.5 \mathrm{~cm}$. in diameter) lesion, which was of a different kind, was present just beneath the pleura. It was very dense, sharply encapsulated, and greyish. Microscopically this tiny lesion was a small necrotic mass in which the alveolar structure was remarkably well conserved. It was encapsulated by fibrous tissue.

The larger lesions showed appearances common to all of them. The central mass was necrotic and no alveolar or fibrillar structure was conserved except in a thin rim at the periphery. Here the alveolar structure was partly conserved. The amorphous central substance was diffusely infiltrated with polymorphs. Acid-fast bacilli were scanty. The peripheral zone of each lesion was a thin one formed of active tuberculous granulation tissue.
The relation of the massive consolidation to the smaller subpleural fozus (probably the primary focus) is of interest but out of place in the present discussion. There is no doubt, however, that towards the end of 1950 A.H. developed tuberculous pneumonia, which instead of resolving or contracting with scar tissue, or instead of rapid spread, remained fairly static for some months, undergoing caseation and in the greater part becoming encapsulated. Apart from the active tuberculous bronchitis and the neighbouring pneumonic disease it is probable, though undetermined, that such encapsulated foci are unsatisfactory and dangerous. The extensive softening with absence of alveolar structure suggests that it is this formation of a round focus that leads to rupture like a co!d abscess and flooding of the bronchi with its dire consequences. This lesion would appear to be similar to the "unripe tuberculoma" as described by Mahon and Forsee (1950, their Case 2). But we believe that this development is different to those described above in our second category. The large area of pneumonia at the onset rather than growth from a smaller focus, and the rapid destruction of structure with liquefaction, are very different from the slow and indolent growth of the laminated round focus.

Occasionally a massive area of consolidation becomes rounded off and encysted. These apparently solitary tumours resemble large intrathoracic growths. Several such "tuberculomata" are des-? cribed in the literature, producing venous obstruction, phrenic paralysis, Horner's syndrome, or even tracheal compression (Norrié, Vivoli, and Rey, ?․ 1936 ; Maurer-Mast and Franklin, 1941). We have not seen such gross examples.

We do not intend to discuss at length the formation and development of blocked cavities. Their behaviour must be influenced by many factors, $\frac{}{5}$ including the nature of the cavity itself and the $\frac{D}{0}$ accompanying tuberculous disease of bronchus and lung. The treachery of such blocked cavities $N$ is well known, but they are also a method of healing. Their development is a frequent occurrence ${ }_{N}$ in the lung under a pneumothorax, and we believe $\omega$ has usually a favourable outcome, as in Case 12 . 을

The natural history of the second type of round ${ }_{C}$ focus will be considered in more detail. It is usual when describing round foci to infer or to define? that they must be of a certain size to be significant. $\frac{T}{0}$ Culver, Concannon, and MacManus (1950) sug- $\frac{\vec{D}}{\vec{D}}$ gest that a focus should be at least $2 \mathrm{~cm}$. in $\frac{?}{\mathbb{C}}$ diameter before being classed as a tuberculoma- $\varrho$ "to prevent further confusion." We believe that such limitation of size serves no useful purpose $\delta$ 
and increases the mystery surrounding them. The origin and development of the smaller foci are identical with those of the larger. The small focus is not necessarily benign nor is the larger focus an inevitable source of spread. That size is a qualifying factor in the frequency with which various events develop is, however, a widely held clinical impression.

Apart from the fact that some round foci may break and lead to fresh infiltration, the relation between these foci and other forms of parenchymal disease is largely ignored. We believe that their recognition accompanying the more common forms of phthisis is important. They may develop within and be shrouded by such disease, and their unsuspected presence may adversely affect treatment. Their presence may be the dominant feature or they may be only incidental findings, recognized to be ignored. Their relative importance in such disease has yet to be assessed.

The possible developments of a round focus may now be reviewed. They may get smaller. Increasing in density, they heal with calcification (Case 13). It is the rule in healing primary foci but also occurs in the reinfection lesion. They may disappear, leaving only a small scar. Size of focus is no bar to such a favourable outcome (Cases $9,10,11$, and 12). It would seem that the result depends on absorption rather than on rupture and dispersal. They may persist for years unchanged in size and density. After a very variable period of quiescence they would then continue their development. They may grow. In our cases where growth had been observed before resection it was found that growth had apparently occurred through the development of layer after layer of encircling tuberculous granulation tissue. Such a growth does not mean a stronger fibrous capsule around a small necrotic centre, for, as each layer is added on, so the inner zones die and add to the necrotic mass. Further, the outermost capsule is one composed of active tuberculous granulation tissue in direct continuity with the healthy lung. The weakness of such a capsule is well shown in Case 4. In this case liquefaction and subsequent rupture into a bronchus has occurred in the part of the focus where growth and proliferation had apparently been greatest, the other necrotic part with a tough fibrous capsule remaining stationary and sealed. The factors responsible for such growth are quite obscure. Its speed, its progress with stops and starts, its cessation, are all very variable.

The healing and activation of disease going on in the same lung at the same time is well known in tuberculosis. Such events are well demonstrated by the round foci. While the accompanying lung disease resolves, the round focus may develop (Cases 6 and 7). At the same time as some round foci shrink and calcify, others grow (Case 13).

They may multiply. It is recognized that a solitary round focus when it comes to detailed examination often shows several outlying and neighbourhood foci. These lesions may be at some distance from the main focus, and can sometimes be recognized by efficient radiology. Larger multiple round foci, easily detected on routine radiography, are, however, by no means rare. They may be confined to one segment or lobe (Case 9) or may be bilateral (Case 13). They may be present at first examination or may reproduce at intervals over years (Case 5). Theif behaviour may be independent of each other, some growing while others heal. Occasionally their development may be entirely different. In Case 6 the smaller lesion is a blocked cavity while the larger growing lesion is a laminated focus.

They may involve the bronchus. This relation has already been discussed above.

They may cavitate. This development is well known. Many workers hold that this is almost inevitable in foci of any size. This view would at times appear to be an impression based on the cases that have gone wrong-rather than a considered opinion based on a study of a large series. Several of our foci showed on radiography small central irregular areas of translucency. Most of these were undoubted air-containing cavities, but in Case 3, following resection, no cavity could be demonstrated. The centre of the lesion contained a milky fluid, and it is possible that the radiological appearances were due to an altered consistency of the centre in contrast to the bulk of the lesion. Whether this change is a prelude to intrabronchial rupture can only be conjectured, but for the present it would seem wise to accept it as an unfavourable sign. The cavities at their start commonly show radiologically the irregular thick walls with scalloped inner margins that by some are said to be characteristic of new growth (Culver and others, 1950).

Cavitation may be accompanied by spread of the parenchymal disease, but this is by no means always the outcome. The cavitation may be a much simpler, uncomplicated, and less dramatic event. It may close spontaneously (Moyes, 1951) or under a pneumothorax, and the focus heal. If the focus was extensively softened before rupture, as appears to occur in glandular cold abscesses bursting into the larger bronchi, then we might 
expect an acute flare-up of disease. But the frequency of such extensive softening in this type of lesion would not appear to be great. It may be that a pulmonary cold abscess has a different development, as suggested in the discussion of Case 15. While their diagnosis would seem impossible in the mature lesion (Mahon and Forsee, Case 2), earlier pictures of the developing focus might provide a valuable clue.

We must be chary of too ready acceptance that the round focus is responsible for the spread of disease. All patients with tuberculous disease are liable to break down. The round and apparently solitary focus is so frequently accompanied by other tuberculous foci in the lung that these radiologically invisible lesions may well be the source of bacilli. It is by no means rare for round foci to heal independently of accompanying active phthisis.

Tuberculomata have been found in many organs of the body. As already mentioned, their nature is sometimes identical with some of those found in the lung. Such visceral granulomata are presumably most often secondary to a primary pulmonary infection. The lung disease, however, in such cases does not seem to react in the same way. There does not appear to be any relation between the occurrence of round foci in the lung and the development of tuberculomata in other organs.

The possible developments of a focus whose nature has been reasonably assessed are known. The frequency of such phases in the natural history of these foci is unknown. Clinical impressions that cavitation is a frequent and disastrous occurrence, or that round foci as a class are innocent and benign, are inadequate and often misleading evidence on which to base a reliable forecast of the group as a whole. A careful prolonged observation of all types and sizes of round foci is required.

Oleneva (1946), in a series of 50 cases observed from one to 10 years, found tubercle bacilli at some stage in $56 \%$. A considerable number showed extensive spread; resolution was rare and prognosis serious. Bobrowitz (1943), in 33 cases observed for an unstated period, found that half of them were unchanged and a third grew smaller. Only two enlarged and three cavitated, all within the first year. Birkelo and Kasper (1937) saw occasional cavitation in 39 cases observed for one to six years. Eriksen (1949) followed up 40 cases over two to 11 years. Thirty-eight remained in good health. Mahon and Forsee (1950) studied the behaviour of 48 cases. They emphasize their potential danger and tendency to cavitate. Moye્s (1951), in a series of 34 unoperated cases, surveye from three to 15 years, found 31 in good health with healing or healed disease, though 17 had showit evidence of activity within the period under review?

These views point the varying opinions on the life of these foci. It will be clear that when we are considering the probable development of $\bar{g}$ hitherto static focus that we are guessing on the unknown. It is the unpredictable alteration in focus that has been dormant for sometimes mank years that has earned these foci their treacherous reputation. It is important that the incidence of unfavourable developments is not exaggerated. 을

There are in many cases signs of instability that should not be overlooked. A recently develope or growing active focus will require careful watch ing. The irregular central translucencies suggestive of cavitation are clearly important, but may onl\$ be detected on tomography. Kerley (1951b remarks on the loss of definition of the out border as a danger sign. Blurred edges of these foci are, however, common in routine posterm anterior films, especially if the focus is toward the periphery of the lung field. Again, if the focu is behind the breast shadow or towards the hilum or if it is anterior, then the lesion may be indistine and indefinite. On tomography the focus is usuall $\vec{B}$ clear-cut. We do not attribute any special sign? ficance to a lobulated focus, but the presence of "pseudopodium" down towards the hilum "along the bronchus" is probably important and ma indicate localized bronchial disease.

Calcification is a frequent finding in heale tuberculosis. A densely calcified lesion may however, still show occasional giant-cell systems in its environs (Haight and Farris, 1939), ang calcification to a considerable degree may be found in a growing lesion (Case 2). Calcification in one half of a round focus may be associate with liquefaction and cavitation in the other (Case. 4). A healing, calcifying focus may be adjacent to an active, growing focus (Case 13). It is clea fo therefore, that calcification must be very care fully assessed. At the present time we believen however, that heavily calcified foci are likely be innocent in their behaviour and their remov may be hazardous (Culver and others, 1950).

A positive bacillary finding in the absence of any other focus is clearly significant, as is also raised E.S.R.

A round focus which has recently develope by the encapsulation of a large area of consolp dation is probably a greater risk than the more common type described above. 
We do not intend to discuss in detail the treatment of round foci. Simple observation, antibiotics, collapse measures, and resection are all used either singly or in combination with a large measure of success by their advocates. The correctness of any particular treatment is often supported by dogmatic assertions on the danger or harmlessness of these lesions. The justification for any form of treatment should be its effect in happily shortening the expected course of the disease for which it is applied. This assessment demands the most careful review of many factors. It would seem to us that there is insufficient knowledge of the natural history of round foci to warrant any confident prediction on their future.

In 1852 Rokitansky wrote that:

"Under certain local and general conditions which are not yet altogeiher understood, tubercles are originally deposited at different spots in groups of a roundish form and of the size of a pea, bean, or hazelnut, or even larger, while around these are other isolated tubercles in greater or lesser number."

To-day, 100 years later, there are still many features of their development which are not altogether understood. Unbiased observation and well-recorded experience will help to define our knowledge.

\section{CONCLUSIONS}

In our experience there are two types of round tuberculous foci, the laminated focus and the blocked cavity.

Having considered the nature and development of these foci, we believe that their treacherous reputation is due largely to our imperfect and uncertain knowledge of their natural history. We list the known behaviour patterns of these foci, but emphasize that their relative frequencies are unknown.

Much more extensive and accurate observation is necessary before their treatment can be based on sound premises.

\section{RFFERENCES}

Albert, A. (1931). Beitr. Klın. Tuberc., 78, 647.

Assmann, H. (1925). Ibid, 60, 527.

Auerbach, O., and Green, H. (1940). Amer. Rev. Tuberc., 42, 707. Bayle, G. L. (1810). Recherches sur la Phthisie Pulmonaire, p. 22. Paris.
Benda. R., Franchel, F., Arnaud, G., and Andreety, P. (1949). Rev. Tuberc., Paris, 13, 946.

Biggart, J. H. (1936). Pathology of the Nervous System, p. 112. Edinburgh.

Birch-Hirschfeld, F. V. (1882). Lehrbuch der Pathologischen Anatomie, 2nd ed., vol. 2, p. 436 . Leipzig.

Birkelo, C. C., and Kasper, J. A. (1937). Radiology, 28, 157.

Bobrowitz, I. D. (1943). Amer. Rev. Tuberc., 47, 472.

Brock, R. C. (1946). The Anatomy of the Bronchial Tree, p. 75. London.

Bruck, S. (1934). Amer. J. Roentgenol., 31, 319.

Burns, D. (1921). PAn Introduction to Biophysics, p. 79. London.

Culver, G. J., Concannon, J. P., and MacManus, J. E. (1950). J. thorac. Surg., 20, 798 .

Epstein, H. H., and Ornstein, G. G. (1936). Quart. Bull. Sea View Hosp., 1, 273.

Eriksen, J. (1949). Nord. Med., 42, 1530.

Galy, P., Bérard, M., and Dumarest, J. (1948). Rev. Tuberc., Paris, 12, 678 .

Gerhartz, H. (1915). Beitr. klin. Tuberk., 34, 191, Fig. 25. (1932). Ibid., 81, 542.

Haight, C., and Farris, J. M. (1939). J. thorac. Surk., 9, 108.

Hecker, H. von, and Kellner, F. (1929). Fortschr. Röntgenstr., 39, 624.

Jacksch-Wartenhorst, R. von (1927). Ibid.. 35, 1043.

Kerley, P. (1951a). A Textbook of X-ray Diagnosis, 2nd ed., ed. S. C. Shanks and P. Kerley, vol. 2, p. 481. London. (1951b). Ibid., vol. 2, p. 479.

Klein, W., and Wolff, K. (1934). Beitr. Klin. Tuberk., 85, 116.

Küss, G. (1898). De l'Hérédité Parasitaire de la Tuberculose Humaine, pp. 361-366. Paris.

Lachmann, E. (1931). Fortschr. Röntgenstr., 43, 407.

Laennec, R. T. H. (1819). [De l'Auscultation Médiate. Paris. 2nd ed. 1826, trans. J. Forbes, 1827 , p. 271 et seq., and p. 378. London.

Loesch, J. (1944). Amer. Rev. Tuberc., 50, 500.

Mahon, H. W., and Forsee, J. H. (1950). J. thorac. Surg., 19, 724.

Maurer-Mast, E., and Franklin, R. M. (1941). Amer. Rev. Tuberc. 43,301 .

Moretti, G. F., and Verdeau, J. (1949). J. Med. Bordeaux, 126, 361.

Morton, R. (1689). Phthisiologia. Eng. trans., 1694, p. 62. London.

Moyes, E. N. (1951). Thorax, 6, 238.

Nassau, E., and Pagel, W. (1951). Tubercle, 32, 120.

Norrié, H., Vivoli, D., and Rey, A. (1936). Rev. Tuberc. Urug., 5, 313.

Oleneva, T. N. (1946). Probl. Tuberk., No. 1, p. 10. Abstracted in Amer. Rev. Tuberc., 1947, 55, Abstract No. 5, p. 136.

Pagel, W. (1931). Dtsch. med. Wschr., 57, 2094.

(1948a). In Kayne, G. G., Pagel, W., and O'Shaughnessy, L., Pulmonary Tuberculosis, 2nd ed., p. 102. London.

(1948b). Ibid., p. 89.

- and Simmonds, F. A. H. (1942). Amer. J. med. Sci., 203, 177.

Rich, A. R. (1944). The Pathogenesis of Tuberculosis, p. 730 et seq. Springfield, Illinois.

Rokitansky, C. (1852). A Manual of Pathological Anatomy, trans. by Day, G. E., vol. 4, p. 105. Sydenham Society. London.

Sellors, T. H., and Hickey, M. D. (1949). Thorax, 4, 82.

Stark, W. (1788). The Works of the late William Stark, M.D., revised by J. Carmichael Smyth, p. 26. London.

Straub, H. (1932). Z. klin. med., 121, 515.

Uehlinger, E. (1939). Beitr. Klin. Tuberk., 92, 170.

Virchow, R. (1858). Die Cellularpathologie. Zwanzig Vorlesungen, p. 423. Berlin.

- (1864-5). Die Krankhaften Geschwülste. Dreissig Vorlesungen, vol. 2, p. 643. Berlin.

Webb, G. B. (1936). Tuberculosis, p. 58 (Clio Medica XVI). New York.

Wessler, H., and Jaches, L. (1923). Clinical Roentgenology of Diseases of the Chest, p. 57 et seq. New York. 